\title{
Adopt or Innovate: Understanding Technological Responses to Cap-and-Trade
}

\author{
By Raphael CALEL*
}

One important motivation for creating cap-and-trade programs for carbon emissions is the expectation that they will stimulate much-needed low-carbon innovation. I construct a new panel of British firms to investigate this hypothesis, finding that the European carbon market has encouraged greater low-carbon patenting and $R \& D$ spending among regulated firms without necessarily driving short-term reductions in carbon intensity of output. This stands in contrast to past cap-and-trade programs, which have primarily spurred adoption of existing pollution control technologies, with little effect on innovation. I discuss how to reconcile these contrasting findings and implications for the future of carbon markets. (JEL D22, O32, O34, Q52, Q54, Q58)

T1 he feasibility of rapidly decarbonizing the world economy rests on the timely development of new low-carbon technologies. Projections show that R\&D spending needs to increase by an order of magnitude by 2030 to meet global climate goals (Rockström et al. 2017). This is one important motivation for the creation of new cap-and-trade programs for carbon emissions (European Commission 2005; Stavins 2007). More than 100 countries have now pledged to put a price on carbon, and more than half of global greenhouse gas emissions could end up covered by cap-and-trade programs once these commitments are fully implemented (World

\footnotetext{
* McCourt School of Public Policy at Georgetown University, Grantham Research Institute on Climate Change and the Environment at the London School of Economics, and the CESifo Research Network (email: raphael. calel@georgetown.edu). Lucas Davis was coeditor for this article. Thoughtful comments from two anonymous referees have immeasurably improved this article. I am also grateful to many colleagues and friends for their feedback on earlier drafts. My thanks to George Akerlof, Robert Akerlof, Antoine Dechezleprêtre, Sam Fankhauser, Meredith Fowlie, Kenneth Gillingham, James Habyarimana, Cameron Hepburn, Michael Hoel, Harry Holzer, Arik Levinson, Carmen Marchiori, Corrado Di Maria, and Karsten Neuhoff as well as seminar participants at Yale University, Georgetown University, and the CESifo Area Conference on Energy and Climate Economics. I owe special thanks to Antoine Dechezleprêtre for assisting in the compilation of patent data, to David Popp for sharing files allowing me to partially replicate his work, and to Sean Paul for assistance with the UK Pollution Inventory. This research would not have been possible without the assistance of Haydn Jones at the UK Environment Agency, the dedicated staff at the UK Data Service as well as funding provided by the ESRC, the Jan Wallander and Tom Hedelius Foundation, and the Ciriacy-Wantrup Fellowship. This work contains statistical data from the Office of National Statistics which is Crown copyright and reproduced with the permission of the Controller of HMSO and the Queen's Printer for Scotland. The UK Data Service agrees that the attached outputs are non-disclosive and cannot be used to identify a person or organization. The original data creators, depositors, or copyright holders, the funders of the Data Collections (if different), and the UK Data Service at the UK Data Archive bear no responsibility for the further analysis or interpretation of the data. This work uses research datasets which may not exactly reproduce National Statistics aggregates. A full replication archive can be accessed through the UK Data Service with their permission. To learn more, go to https://www.ukdataservice.ac.uk/get-data/how-to-access/accesssecurelab.

${ }^{\dagger}$ Go to https://doi.org/10.1257/pol.20180135 to visit the article page for additional materials and author disclosure statement(s) or to comment in the online discussion forum.
} 
Bank 2017). Yet when past cap-and-trade programs have been implemented-to regulate $\mathrm{SO}_{2}, \mathrm{NO}_{X}$, lead, and ozone-depleting substances-the emissions reductions mainly resulted from adoption of techniques and equipment that were readily available. There was negligible development of new technologies (Taylor 2012). This paper asks whether carbon markets are repeating this historical pattern. The absence of an innovation response would present a serious challenge to meeting global climate goals.

In this paper, I examine firms' technological responses to the world's largest carbon market-the European Union's Emissions Trading System (EU ETS). Early carbon trading experiments such as the EU ETS have naturally garnered a great deal of interest (Schleich and Betz 2005; Gagelmann and Frondel 2005; Grubb, Azar, and Persson 2005), but no study to date has been able to look comprehensively at firms' responses: their adoption of existing abatement technologies as well as their innovation of new ones. I have assembled a new dataset that links administrative data on British firms with business surveys and regulatory records. This is the largest firm-level database yet on three important measures of technology adoption and innovation: $\mathrm{CO}_{2}$ intensity of production, low-carbon patenting, and low-carbon R\&D expenditures. These measures provide the best picture yet of how firms have responded to the EU ETS.

I present evidence that relative to historically similar firms, the firms whose plants came under the EU ETS (i) do not appear to have adopted off-the-shelf low-carbon technologies on any substantial scale, but (ii) they have increased their low-carbon patenting and R\&D spending by roughly 20-30 percent. Under the conservative assumption that only the directly regulated firms responded to the EU ETS, my estimates imply that the program was responsible for an additional $£ 350-£ 450$ million in total R\&D spending and 100-150 patents in 2005-2012. These estimates provide a lower bound, and the total effects could be as much as twice this once we take account of innovations by firms that were not directly regulated by the EU ETS.

To identify the effects of the EU ETS, I exploit two features of its implementation in Britain. First, only the firms that operate at least one "large" plant are required to comply with the EU ETS, even though firms that operate smaller plants may be just as large in total, as polluting, and as innovative. I estimate the EU ETS's effects on adoption and innovation by comparing initially similar firms that were regulated differently because one of them, but not the other, operated a plant larger than the EU ETS size thresholds. Second, the EU ETS thresholds differed sufficiently from Britain's preexisting climate regulations so that many firms previously covered by the same regulations suddenly became subjects of different ones. Thus my setting allows me to condition on past policies at the firm level and isolate the EU ETS's effects relative to those other carbon policies, something that has not been possible elsewhere.

This identification strategy exploits thresholds that affect the largest and most polluting firms, so getting precise estimates depends on having a large starting population. I have assembled data on the universe of 6 million British firms active between 2000 and 2012, from which I have culled about 900 firms - half EU ETS and half non-ETS - that operate in proximity to these thresholds. A sample of this size would 
usually be more than adequate for obtaining considerable precision. But since low-carbon patenting and R\&D spending are rare activities for firms to undertake, my estimates are more suggestive than definitive. The economic magnitudes are sensitive to specification, in some cases shrinking toward zero. Nevertheless, they have qualitative consistency. The direction of my point estimates appears to be robust.

The contrast between the effects I observe under the EU ETS compared to what others have observed under past cap-and-trade programs may rest on the fact that the EU ETS regulates carbon, a pollutant of relatively recent concern, whereas past programs addressed pollutants that were already targets of long-standing command-and-control regulations. So in past programs, firms were able to adopt abatement technologies that had matured under prior regulations, whereas technology development naturally plays a bigger role for carbon dioxide.

A positive effect on innovation would have hopeful implications for the future of carbon markets. Cost savings from adoption plus innovation will be greater than from adoption alone. Future reductions in abatement costs therefore could be greater than experience from previous cap-and-trade programs suggests. Lower costs of cutting carbon would make more ambitious emissions caps feasible, giving us a better chance of avoiding the worst effects of climate change.

\section{Related Literature}

According to the induced innovation hypothesis, a higher relative price of a factor of production spurs innovation that reduces the use of that factor. Along such lines, following Porter (1991), a considerable literature has emerged on the effects of environmental regulations on technological change (Palmer, Oates, and Portney 1995; Ambec et al. 2013), especially in the context of climate change mitigation (Acemoglu et al. 2012, Aghion et al. 2016). Despite broad empirical support for such induced innovation (Jaffe and Palmer 1997; Newell, Jaffe, and Stavins 1999; Berman and Bui 2001; Popp 2002; Brunnermeier and Cohen 2003), empirical studies of cap-and-trade programs have found little effect on the development of new technologies. They reduced emissions, instead, by encouraging adoption of available abatement techniques and equipment.

\section{A. Evidence from Past Cap-and-Trade Programs}

The Acid Rain Program - a major cap-and-trade program for $\mathrm{SO}_{2}$ emissions from US coal plants that began in 1995-encouraged firms to adopt readily available flue-gas desulfurization technology (or "scrubbers") and to purchase coal with a lower sulfur content (sometimes known as "blending") (Schmalensee et al. 1998).11 Panel A1 of Figure 1 shows a large spike in adoption of scrubbers at the introduction of the Acid Rain Program, and panel A2 shows how the share of low-sulfur coal

\footnotetext{
${ }^{1}$ Sometimes blending is referred to as a form of innovation (e.g., Burtraw 2000). I consider it to be adoption in line with the definition offered above and elaborated on in Section II.
} 
Acid rain program
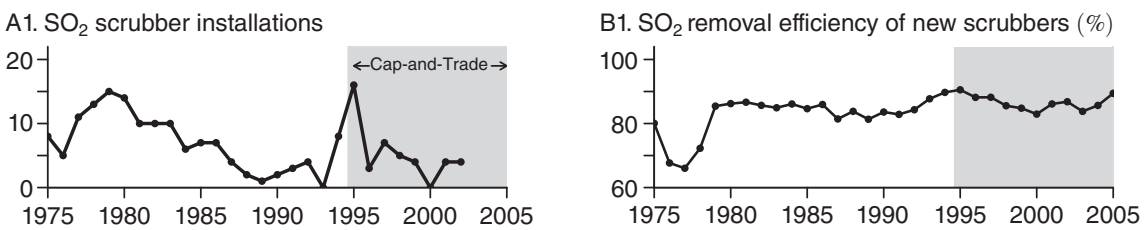

A2. Low-sulfur coal production (\%)

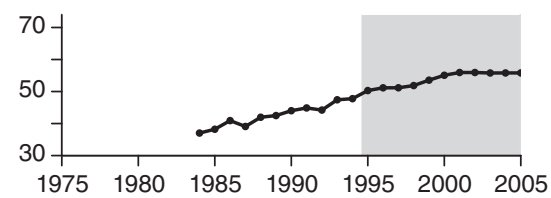

B2. Patents for $\mathrm{SO}_{2}$ abatement technologies

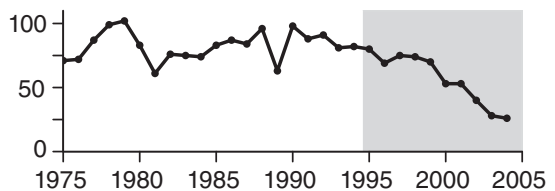

$\mathrm{NO}_{X}$ budget trading

A3. SCR installations

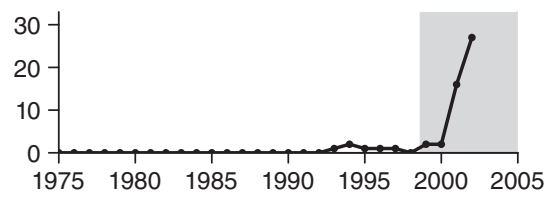

B3. Patents for $\mathrm{NO}_{x}$ abatement technologies

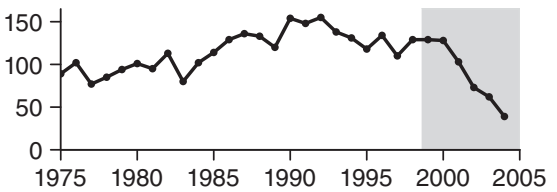

EPA lead trading

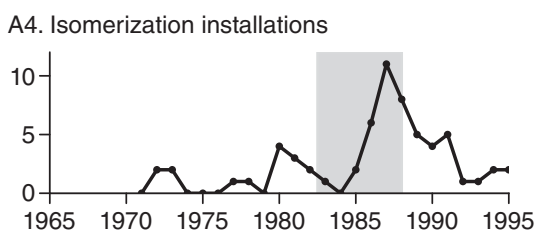

B4. Isomerization cost index $(1971=100)$

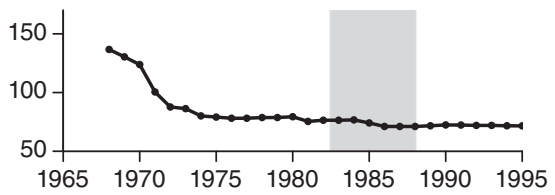

Figure 1. Adoption and Innovation in Past Cap-and-Trade Programs

Notes: These graphs are meant only as illustration of the findings from the empirical literature. Panels A1, A3, B2, and B3 are adapted from Taylor (2012). Panel A2 is adapted from Energy Information Administration (EIA) (2009). Panel B1 replicates and extends Popp (2003) using information from the EIA-767 forms (as in Popp, I show a three-year moving average). Panels A4 and B4 are adapted from Kerr and Newell (2003).

continued through the transition. ${ }^{2}$ Although patenting for higher-efficiency scrubbers increased as a proportion after the 1990 Clean Air Act Amendments were passed (Popp 2003), the efficiency of newly installed scrubbers actually declined after the surge of installations in the mid-1990s (B1). Overall, patenting for low-sulfur technologies declined substantially after the introduction of cap-andtrade (B2) (Taylor 2012). Most improvements in the performance and capital costs of scrubbers occurred well before the Acid Rain Program came into effect

\footnotetext{
${ }^{2}$ The graphs collected in Figure 1 are synthesized from the empirical literature to illustrate its main conclusions. The conclusions themselves, however, are based on a much more comprehensive and rigorous assessment of available data.
} 
(Taylor, Rubin, and Hounshell 2003, 2005). Nor did the program boost other low-emission technologies (Hanemann 2010). Moreover, some of the US patents protected inventions from other countries that regulated $\mathrm{SO}_{2}$ by means other than cap-and-trade (Dekker et al. 2012).

Studies of other cap-and-trade programs tell a similar story. The $\mathrm{NO}_{X}$ Budget Trading Program spurred adoption of selective catalytic reduction (SCR) technology (A3) (Fowlie, Holland, and Mansur 2012), but patenting for SCR and other $\mathrm{NO}_{X}$-control technologies fell dramatically (B3) (Taylor 2012). The Environmental Protection Agency's (EPA) market-based phaseout of leaded petroleum stimulated adoption of the main substitute technology, pentane-hexane isomerization (A4), but the cost of the equipment did not come down markedly (B4), nor were any noteworthy new technologies introduced (Kerr and Newell 2003). When markets for chlorofluorocarbons were set up in the late 1980s, an economically competitive replacement, hydrochlorofluorocarbons, already existed (Gorman and Solomon 2002). Most industries modified their production processes with little difficulty, and where necessary technological advances did occur, they are attributable to investments made well before the trading program was in place (Falkner 2008).

These cap-and-trade programs were implemented at different times, for different industries and pollutants, and required different abatement technologies. Yet there is a consistent pattern. Firms favored adoption over innovation.

\section{B. Evidence from the EU ETS}

Early studies of the EU ETS suggested that emissions reductions could be largely explained by fuel switching in the power sector (Delarue, Ellerman, and D'haeseleer 2010; Delarue, Voorspools, and D'haeseleer 2008). By bringing gas-fired plants online before coal-fired ones, the power producers could reduce the $\mathrm{CO}_{2}$ intensity of output. That is a story of adoption. However, more recent research reaches the opposite conclusion. Studies of regulated firms in Sweden (Widerberg and Wråke 2009, Löfgren et al. 2013), Norway (Klemetsen, Rosendahl, and Jakobsen 2016), Lithuania (Jaraitė and Di Maria 2016), and Ireland (Jaraite and Di Maria 2011) have all struggled to find evidence that the EU ETS has encouraged adoption and any reduction in the $\mathrm{CO}_{2}$ intensity of output. ${ }^{3}$

Findings on innovation are likewise contradictory. Early case studies and expert interviews found that firms were not putting resources into development of new low-carbon technologies (Hoffmann 2007; Tomás et al. 2010; Anderson, Convery, and Di Maria 2011). These findings were bolstered by evidence from patent data (Aghion, Veugelers, and Serre 2009). However, more recent studies with larger, more disaggregated datasets have found that EU ETS firms are investing in low-carbon innovation (Martin, Muûls, and Wagner 2011; Calel and Dechezleprêtre 2016).

\footnotetext{
${ }^{3}$ These findings do not contradict evidence that ETS-regulated firms have reduced the absolute level of emissions of regulated firms in Germany (Petrick and Wagner 2014), France (Wagner et al. 2014), and Norway (Klemetsen, Rosendahl, and Jakobsen 2016). The 2008 recession likely would have produced reductions even in the absence of adoption.
} 
Panel A. Adoption

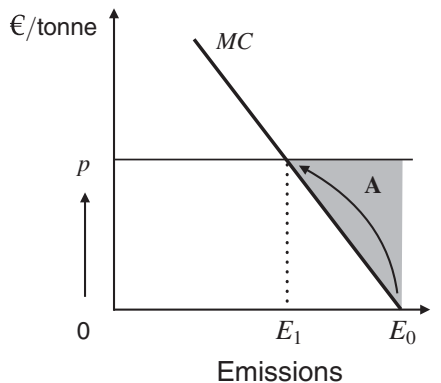

Panel B. Innovation

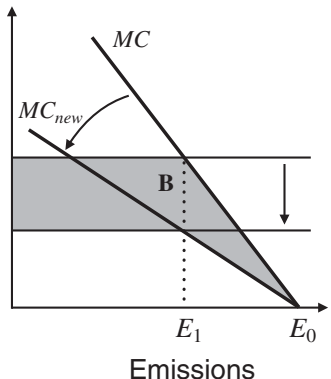

FiguRE 2. INCENTIVES FOR ADOPTION AND INNOVATION

Notes: In the absence of a regulatory constraint, a firm will produce emissions $E$ up to the point where the marginal benefit from emissions goes to zero, $E_{0}$. The curve $M C$ shows the marginal cost of reducing emissions below $E_{0}$. A firm that becomes regulated under a cap-and-trade program is faced with paying $p$ to obtain allowances at the margin but can reduce its compliance cost by adopting all abatement technologies with a marginal cost below the allowance price $p$. The shaded area $\mathbf{A}$ shows the gain from doing so. Innovation increases the availability of abatement technologies, illustrated as a pivot of the $M C$ curve in the right-hand panel. Since the technology frontier shifts for all firms, innovation reduces aggregate demand for allowances, and the price $p$ falls. The shaded area $\mathbf{B}$ shows the reduction in a regulated firm's compliance cost that results from this innovation. See Requate (2005) for a standard treatment of the incentives to adopt and innovate under cap-and-trade.

The findings of these previous studies-which use different methodologies to obtain estimates from different countries and sectors-are difficult to reconcile. It is especially difficult to form a comprehensive picture of firms' technological responses as no single study has looked at adoption and innovation together. This paper fills that gap.

\section{Basic Theory}

So far, I have used "adopt" and "innovate" to refer loosely to the use of existing abatement technologies and the development of new ones. Figure 2 represents the conceptual distinction. Adoption moves a firm along its marginal abatement cost curve; after adopting the cheapest available abatement option, it faces a higher marginal cost for the next increment of abatement. By contrast, innovation expands the technology set and creates opportunities for greater abatement at a given marginal cost. This shifts the marginal abatement cost curve inward.

For a firm under a cap-and-trade program, the shaded area $\mathbf{A}$ represents the savings from adopting the cheaper abatement options instead of purchasing the emissions allowances needed to cover its uncontrolled emissions. Firms not subject to the cap have no comparable incentive. Even if the emissions price is passed on to unregulated firms in the form of higher product prices, this incentivizes them to adopt technologies that rely less on pollution-intensive intermediate goods rather than technologies that reduce their own emissions.

A firm regulated under a cap-and-trade program can expect to earn a surplus $\mathbf{B}$ if it innovates. Its gains come both from the lower abatement costs for a given level of abatement and from a lower emissions price that occurs when the new technology comes into general use and reduces aggregate demand for emissions allowances. 
The emissions price will also incentivize firms that are not regulated by the cap, since uncapped firms can profit by selling the new emissions-saving technology to capped firms. As long as a third-party innovator cannot fully extract the capped firm's surplus, though, the same emissions price will provide weaker innovation incentives for uncapped firms. ${ }^{4,5}$ Theory does not tell us whether the wedge between the innovation incentives of capped and uncapped firms is large or small, but Dechezleprêtre and Glachant (2014) and Calel and Dechezleprêtre (2016) find it is big enough to be empirically relevant.

Whether a cap-and-trade program will primarily encourage adoption or innovation will depend on the current abatement options (captured by the shape of the marginal abatement cost curve) and potential technological innovations (captured by the inward shift of the curve). ${ }^{6}$ Nevertheless, this stylized framework gives us a lens for viewing the body of evidence. In past programs, available technologies were sufficient to meet mandated emissions caps at reasonable cost, and the cap-and-trade programs allowed firms enough flexibility to choose this lower-cost strategy. The emphasis on adoption is rightly seen as evidence of their success (Burtraw 2000). It also implies, though, that past programs do not furnish a good test of whether cap-and-trade can induce innovation when it is needed. If the curves for low-carbon technologies are sufficiently different from those in previous programs, the response could be qualitatively different.

This simple model also makes one important prediction. A cap-and-trade program encourages adoption or innovation more strongly for capped than uncapped firms. The point is straightforward for adoption, but it also extends to innovation. Of course, to the extent that unregulated inventors can extract a portion of the innovation surplus, a cap-and-trade program can encourage third-party innovation as well. A comparison between regulated and unregulated firms will then produce conservative estimates for the program's total effect. Nevertheless, for firms with similar levels of patenting and R\&D spending prior to the new regulation-which ensures

\footnotetext{
${ }^{4}$ It is a standard assumption that an innovator cannot completely appropriate the gains from a new technology (Milliman and Prince 1989; Fischer, Parry, and Pizer 2003). Transactions costs, asymmetric information, substitutability, and the fact that the gains from innovation partly come about through lower emissions prices all dissipate the rents that an inventor can extract. The degree of appropriability may be especially low for clean technologies, where technological spillovers are typically larger (Dechezleprêtre, Martin, and Mohnen 2014). Moreover, introducing a new abatement technology into a plant can require substantial in-house development, which a third-party innovator does not provide. If only the "research" portion of $\mathbf{B}$ is appropriable but not the "development" portion, this further reduces the share of $\mathbf{B}$ that a third-party inventor can extract. This would be consistent with evidence that internal R\&D is more valuable to firms (Arora, Belenzon, and Sheer 2017). If there is emphasis on process innovations, which may not be sold at all, the appropriable fraction of $\mathbf{B}$ could approach zero. Regulation also can increase the salience of pollution management within regulated firms compared to unregulated ones, leading them to be more aware of the costs of regulation (Martin et al. 2012) and to have systematically higher estimates of the gains from innovation, B (Martin, Muûls, and Wagner 2011).

${ }^{5}$ Selling new low-carbon technologies to capped firms is not the only reason why an uncapped firm will have an incentive to innovate. If the emissions price makes pollution-intensive intermediate goods, such as electricity, more expensive, they will have an incentive to develop technologies that use less of these inputs. This indirect effect primarily concerns energy-saving technologies rather than emissions-saving technologies, however, which are not the main focus here. Moreover, higher electricity prices would induce parallel increases in the incentives for capped and uncapped firms and leave the difference between them unaffected. This effect would not affect my estimates, therefore, but does imply they might not fully capture the total effect of the cap-and-trade program. I return to this issue later in the discussion of results and robustness.

${ }^{6}$ Similarly, a more stringent emissions cap could favor either adoption or innovation, depending on how these curves are drawn.
} 
they balance the benefits and costs of innovation at the same level - the wedge introduced by a cap-and-trade program provides a way to empirically identify whether the EU ETS has had an effect.

\section{Data and Methods}

\section{A. Policy Background}

The design of the EU ETS plays a central role in my empirical strategy, so it is essential to understand how the program was rolled out in Britain.

Britain is one of Europe's largest polluters, housing roughly 1,200 of the 12,000 plants regulated under the EU ETS. But even before the program launched in 2005, Britain already had three carbon pricing policies in place: the Climate Change Levy (CCL), Climate Change Agreements (CCAs), and the UK Emissions Trading Scheme (UK ETS). The CCL was a tax on commercial energy use, amounting to an implicit carbon tax ranging from $£ 4.50$ to $£ 8.50$ per tonne of $\mathrm{CO}_{2}$ depending on the energy source (Bowen and Rydge, 2011). The CCAs were sector-wide agreements to which individual plants could be signed up. A firm would thereby commit to reducing emissions at that plant by a prespecified amount and would in turn receive an 80 percent discount on its CCL bill. Once a firm signed onto a CCA, it also became eligible to trade its CCA-specified emissions quota in the UK ETS. The government also purchased additional abatement commitments from a small number of non-CCA plants through a reverse auction. The 32 firms that won contracts through this auction, known as "Direct Participants," could also trade their emissions quotas in the UK ETS (Comptroller and Auditor General of the National Audit Office 2004).

The EU ETS was expected to provide greater incentives for adoption and innovation but did not replace all these policies at once. Rather, plants participating in the UK ETS were exempted from the EU ETS until 2007, and plants covered by CCAs were exempted until 2008. As the exemptions expired, the number of firms with EU ETS-regulated plants grew from 272 in 2005 to 445 in 2008 (illustrated by the shading in Figure 3). Crucially for identification, the EU ETS used different thresholds to determine eligibility. Participation in a CCA therefore did not perfectly predict EU ETS status. The same goes for participation in the UK ETS and a firm's CCL bill. When a firm entered into the EU ETS, then-in 2005, 2007, or 2008 - another one with the same regulatory history typically remained outside of the EU ETS.

This makes it possible to condition comparisons of EU ETS and non-ETS firms on prior regulations but also cautions us against thinking of the non-ETS condition as totally unregulated. As a counterfactual, we should imagine that EU ETS firms would instead have been subject to the policies experienced by similar firms outside the program..$^{7}$ This helps to answer the policymaker's question of whether cap-and-trade encourages adoption and innovation beyond preexisting policies.

\footnotetext{
${ }^{7}$ Note that if the earlier carbon policies were more stringent, the EU ETS could theoretically reduce the incentives for adoption and innovation. Although I have described a cap-and-trade program as inducing innovation, the
} 
Panel A. Efficiency

Tonnes of $\mathrm{CO}_{2}$ and employees per $£ 1,000$ of gross value added

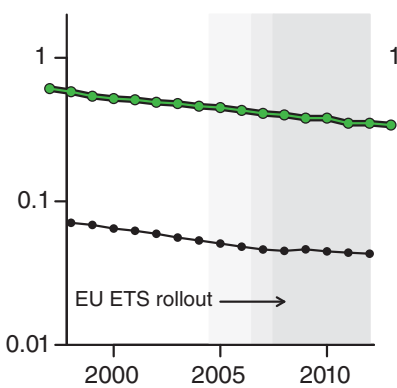

Panel B. Patents

Low-carbon and other

Total number

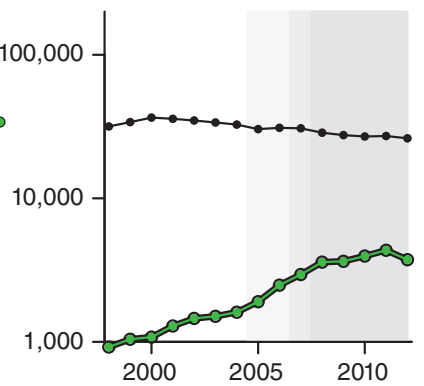

Panel C. R\&D

Low-carbon and total Million $£$

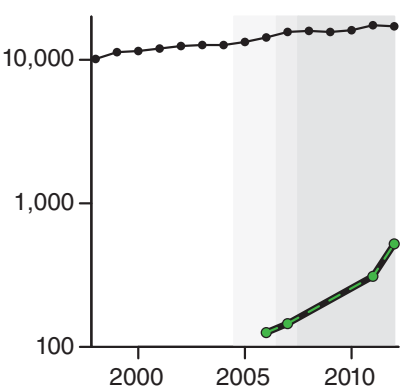

Figure 3. Trends in EFficiency and InNOvation

Notes: The darkening gray shading indicates the growing number of firms that operated plants regulated under the EU ETS over time. There were 272 ETS firms as of 2005, 278 as of 2007, and 445 as of 2008. Panel A plots the average number of tonnes of $\mathrm{CO}_{2}$ emitted (in green, or gray when printed in black and white) and people employed (in solid black) by British industry per $£ 1,000$ of gross value added, obtained from the Office of National Statistics. Panel B plots the annual counts of UK patents filed by British firms to protect low-carbon technologies (in green, or gray when printed in black and white) and to protect all other technologies (in black), obtained from PATSTAT. Panel C plots total corporate R\&D spending and that part specifically directed toward developing low-carbon technologies. Estimates of total corporate $R \& D$ spending are obtained from Eurostat, while estimates of corporate low-carbon R\&D spending are collected from Weisenthal et al. (2009, 2012), Corsatea et al. (2015), and Fiorini et al. (2016), four studies that use a broadly consistent methodology to produce single-year estimates. The four estimates are connected by a dashed line to make it easier to see the trend, but they do not strictly form a single time series.

\section{B. Data}

Adoption and innovation can be challenging to measure. When the set of germane abatement strategies is small, it may be possible to observe adoption directly, as I do in Figure 1. More generally though, adoption can be inferred from its consequence; firms emit less per unit of output. The absolute level of emissions is likely to be a poor indicator of adoption because output generally rises and falls for reasons unrelated to adoption, such as the business cycle. Emissions intensity will better proxy adoption decisions as long as emissions are locally proportional to output. 8

Innovation is more difficult to distill into a single metric, which means there is an advantage to looking at multiple measures together (Martin 1996; Hagedoorn and Cloodt 2003; Lanjouw and Schankerman 2004; Arvanitis, Donzé, and Sydow 2010). Patenting has been used extensively to measure innovation output (Popp 2002, 2006; Johnstone, Haščič, and Popp 2010), while R\&D expenditures are used to measure innovation input (Chavas, Aliber, and Cox 1997; Hirshleifer, Hsu, and

effect could be negative in a more crowded policy space. In practice, it would be surprising to find a negative effect since the EU ETS was thought to be a more stringent policy that would encourage greater adoption and innovation. But whether the effect is positive or negative, the difference between capped and uncapped firms will still measure the effect of the EU ETS relative to the policies experienced by similar firms outside the program.

${ }^{8}$ Output can rise or fall in response to the emissions price too. Producing less is a valid strategy to reduce emissions, but I do not consider it a form of adoption. This is one more reason to favor emissions intensity as a proxy. Since output reduction would reduce both the numerator and denominator in equal proportion, it would not be counted as evidence of adoption. In practice, output reduction is so expensive at the margin anyway that it is unlikely to be used as an abatement strategy under a cap-and-trade program like the EU ETS. 
Li 2013; Arora, Belenzon, and Sheer 2017). Patenting and R\&D both have the advantage of being technology specific, so that it should in principle be possible to distinguish low-carbon innovation from innovation in other areas. These measures obviously do not fully capture all aspects of innovation, but they provide useful proxies for firms' efforts and success in expanding the technology set (see OECD 2009 and OECD 2015 for surveys).

Figure 3 shows how these measures of adoption and innovation evolved in Britain during the period covered in this study. Panel A shows substantial economy-wide reductions in $\mathrm{CO}_{2}$ intensity in this period. From 2000 to 2010, the $\mathrm{CO}_{2}$ intensity of British industry fell by 25 percent. But there was no obvious break in the trend around the time the EU ETS was implemented, and the decline in $\mathrm{CO}_{2}$ intensity was mirrored by declines in labor intensity, suggesting it may reflect generic efficiency improvements.

Measures of innovation exhibit a different pattern (although it is somewhat muted by the logarithmic scale). The number of low-carbon patents (panel B) was growing at 9 percent per year in the early part of the decade, but the growth rate more than doubled in 2005, a change that was sustained for the next few years before eventually settling back to 9 percent by the end of the decade. There is a clear structural break in 2005 ( $F$-test, $p=0.003$ ). Meanwhile, the number of patents filed to protect all other technologies changed more slowly throughout the period, with no apparent break in trend. As a result, the share of low-carbon patents rose from 3 percent in 2000 to 13 percent in 2010.

To distinguish low-carbon patents from all other patents, I use a new patent class - the Y02 class - developed by the European Patent Office (EPO). This patent class is the result of an unprecedented effort by patent examiners and external experts specialized in each technology to develop a tagging system for all patents ever filed at the EPO that relate to climate change mitigation..$^{9}$ The focus is on technologies with potential to reduce or prevent greenhouse gas emissions directly-for example, renewable energy generation, biofuel production, nuclear, carbon capture and storage, and combined heat and power. The Y02 class also includes some technologies aiming to improve energy efficiency, though to a much lesser degree. ${ }^{10}$ This provides the most accurate tagging of climate change mitigation patents available today and is becoming the international standard for research on low-carbon innovation.

Corporate R\&D spending seems to display a similar pattern to patents (Figure 3, panel C). ${ }^{11}$ Though we lack official statistics prior to 2005, corporate low-carbon R\&D spending quadrupled after implementation of the EU ETS, with annual growth

\footnotetext{
${ }^{9}$ Patents are designated as "low-carbon" by the patent office without consulting the inventor, so a firm that becomes regulated has no ability to reclassify patents (nor would they have an incentive to do so since the regulator does not track this). Importantly, the tagging is applied consistently to patents filed both before and after the EU ETS was introduced. See Veefkind et al. (2012) for additional details, as well as the online Appendix.

${ }^{10} \mathrm{~A}$ small number of Y02 subclasses include energy efficiency patents. Beyond these, some patents cannot be easily categorized as reducing emissions or energy use. A single patent can be tagged in multiple technology categories, or the technology can have different effects depending on its application, e.g., new building insulation materials reduce emissions in buildings heated by traditional boilers but save electricity for electrically heated buildings. I estimate that at most, 12 percent of Y02 patents are primarily energy efficiency patents. See the online Appendix for a more detailed description of the Y02 class.

${ }^{11}$ Here, I use the definition from Wiesenthal et al. $(2009,15)$, who estimate "industrial R\&D investments directed towards SET-Plan priority technologies in the EU. These comprise wind energy; concentrating solar power
} 
rate greater than 25 percent. ${ }^{12}$ Total corporate $R \& D$ spending grew at a more modest rate of 3 percent per year, although it grew much faster in 2006 and 2007 (15 percent and 10 percent, respectively). Most of this growth spurt vanishes if we net out the low-carbon R\&D figures from the annual totals, suggesting that the faster growth may primarily be a consequence of rising low-carbon R\&D spending.

These statistical aggregates provide an informative starting point, but it would be naïve to attribute these patterns to the EU ETS without first accounting for other factors that affect adoption and innovation. For instance, the price of oil rose sharply over the same period, as did the amount of government-funded R\&D (Figure 4). Both are known drivers of low-carbon innovation. Because these factors could confound the aggregate trends, identifying the effects of the EU ETS requires us to distinguish more carefully between the outcomes of the firms that became regulated under the EU ETS and those that did not.

I have constructed a new dataset for this purpose, merging several restricted-access micro-datasets held by UK Data Service ${ }^{13}$ with the EPO Worldwide Patent Statistical Database as well as regulatory databases gathered from the UK's Environment Agency, Department of Energy and Climate Change (DECC), and the European Commission. Aside from standard firm characteristics, such as revenues and employment, this database includes several key measures of adoption and innovation. Due to the wide range of sectors and activities that are being regulated under the EU ETS, I do not measure adoption of individual abatement technologies but rather observe firms' $\mathrm{CO}_{2}$ intensities. I use both patenting and $\mathrm{R} \& \mathrm{D}$ spending to try to get a clearer empirical signal of the innovation response. The EPO's Y02 class identifies patents protecting low-carbon technologies, and DECC's low emissions R\&D survey measures R\&D spending devoted specifically to low-carbon technologies. ${ }^{14}$ I also keep track of labor intensity, total patenting, and total R\&D spending to see whether adoption and innovation in low-carbon technologies have crowded out investments elsewhere.

The full dataset covers more than 6 million firms active between 2000 and 2012, although data are missing for many variables and years due to the varying coverage of the underlying datasets and inactivity by many firms for part of the period. This is one place where one can imagine low-cost measures that would substantially

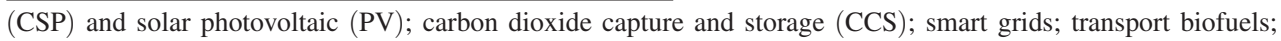
hydrogen and fuel cells; nuclear fission (with a focus on generation IV reactors); and nuclear fusion."

${ }^{12}$ This estimate is based on four studies that use a broadly consistent methodology to produce single-year estimates (Wiesenthal et al. 2009, 2012; Corsatea et al. 2015; Fiorini et al. 2016). The Business Enterprise Research and Development (BERD) survey compiled by Eurostat reports corporate R\&D spending by the energy sector. This is sometimes used as an alternative proxy for corporate low-carbon R\&D spending. It excludes much of corporate low-carbon R\&D and includes things that would not be classified as low carbon. Yet for comparison, this time series had an annual growth rate of 11 percent between its inception in 2007 and 2012.

${ }^{13}$ The Business Structure Database (Office for National Statistics 2012), the Quarterly Fuels Inquiry (Department of Energy and Climate Change 2011), the UK Innovation Survey (Department for Business, Innovation and Skills, Office for National Statistics, and Northern Ireland Department of Enterprise, Trade and Investment 2012), the BERD survey (Office for National Statistics 2011), and the DECC Low Emissions R\&D Survey (Department of Energy and Climate Change and Office for National Statistics 2012).

${ }^{14}$ DECC's low emissions R\&D survey defines the term as "R\&D activity undertaken with the main purpose of reducing carbon dioxide and other greenhouse gas emissions. Included in this definition is the trialing of a new material, product or process in a pre-commercial working environment, often referred to as deployment and demonstration." The full survey instrument is made publicly available through the UK Data Service (Department of Energy and Climate Change and Office for National Statistics 2012). 


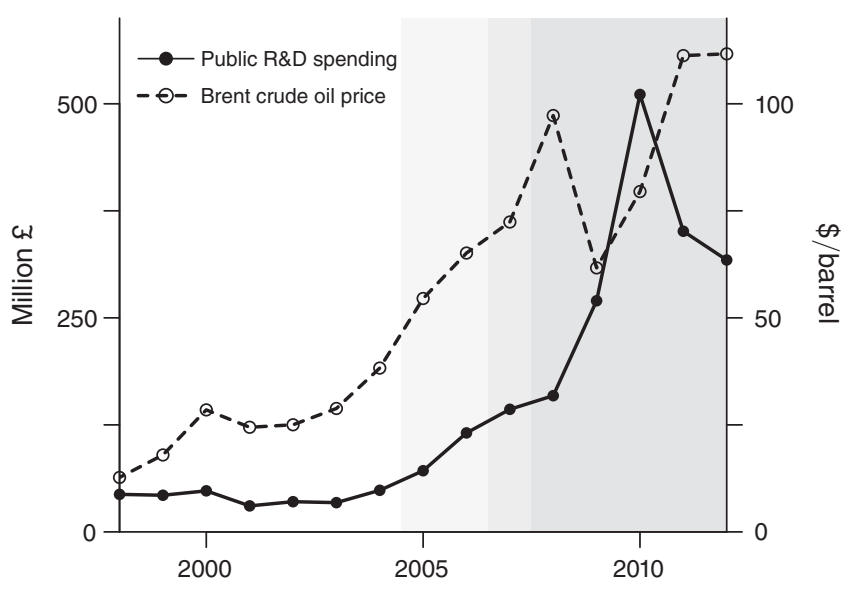

Figure 4. Potential Confounders

Note: As in Figure 3, the shading indicates the increasing number of firms that became regulated under the EU ETS as the program was rolled out in the United Kingdom.

Sources: Annual public R\&D spending is taken from the International Energy Agency, and annual average oil prices are from the BP Statistical Review (Dudley 2015).

improve the scope for future evaluations, such as strategically expanding fuel-use and $\mathrm{R} \& \mathrm{D}$ surveys to cover a higher proportion of the firms that are to be regulated under some new program as well as more of their unregulated competitors. This is especially valuable for activities that are rare and rarely surveyed, such as low-carbon R\&D. The database identifies firms regulated under Britain's prior domestic climate change policies as well as 445 firms that operated plants regulated under the EU ETS. ${ }^{15}$

Table 1 summarizes the firm characteristics and data availability prior to 2005 . EU ETS firms were far from representative of the business community at large. They had on average 650 times greater annual revenues than the average firm and 260 times as many employees. Firms in the electricity and gas sector (7 percent) and in manufacturing (49 percent) are heavily overrepresented. Data on efficiency and R\&D spending are much more limited but indicate that would-be EU ETS firms emitted nearly four times as much $\mathrm{CO}_{2}$ per $£ 1,000$ of revenue and employed only half as much labor. They filed patents at substantially higher rates than other businesses and invested much more heavily in R\&D. The fact that these firms already had substantial innovation capacity supports the expectation that they would respond to the EU ETS by, at least to some degree, innovating in-house.

\footnotetext{
${ }^{15}$ These firms collectively operated 992 EU ETS-regulated plants. I exclude 216 other British EU ETS-regulated plants that were operated by hospital trusts, city councils, the Ministry of Defence, and other nonfirm entities. Their behavior is beyond the scope of this study.
} 
Table 1-Average Annual Firm Characteristics before the EU ETS, 2000-2004

\begin{tabular}{|c|c|c|c|c|c|c|}
\hline & \multicolumn{3}{|c|}{$\begin{array}{l}\text { EU ETS firms } \\
(N=445)\end{array}$} & \multicolumn{3}{|c|}{$\begin{array}{c}\text { Non-ETS firms } \\
(N=6,022,188)\end{array}$} \\
\hline & Mean & $\mathrm{SD}$ & $\%$ missing & Mean & SD & $\%$ missing \\
\hline \multicolumn{7}{|l|}{ Firm basics } \\
\hline Revenues $^{\mathrm{a}}(£ 1,000)$ & 770,417 & $2,795,245$ & 18 & 1,191 & 94,127 & 39 \\
\hline Employees ${ }^{\mathrm{a}}$ & 2,349 & 8,081 & 18 & 9 & 282 & 39 \\
\hline Electricity and gas ${ }^{\mathrm{a}}$ & 0.07 & 0.25 & 0 & $<0.01$ & 0.01 & 0 \\
\hline Manufacturing ${ }^{\mathrm{a}}$ & 0.49 & 0.50 & 0 & 0.06 & 0.23 & 0 \\
\hline Agriculture and services ${ }^{\mathrm{a}}$ & 0.23 & 0.42 & 0 & 0.63 & 0.48 & 0 \\
\hline \multicolumn{7}{|l|}{ Efficiency } \\
\hline $\mathrm{CO}_{2}$ intensity ${ }^{\mathrm{a}, \mathrm{b} *}\left(\mathrm{tCO}_{2} / £ 1,000\right)$ & 0.42 & 0.62 & 78 & 0.11 & 0.21 & 99 \\
\hline Labor intensity ${ }^{\text {a }}($ employees $/ £ 1,000)$ & 0.01 & 0.01 & 20 & 0.02 & 0.02 & 43 \\
\hline \multicolumn{7}{|l|}{ Patenting } \\
\hline Low-carbon $^{\mathrm{c}}$ & 0.11 & 1.13 & 0 & $<0.01$ & 0.01 & 0 \\
\hline Total $^{\mathrm{c}}$ & 2.61 & 16.05 & 0 & $<0.01$ & 0.12 & 0 \\
\hline \multicolumn{7}{|l|}{ R\&D spending } \\
\hline Low-carbon ${ }^{\mathrm{d}}(£ 1,000)$ & - & - & 100 & - & - & 100 \\
\hline Total $^{\mathrm{e}, \mathrm{f} * *}(£ 1,000)$ & 20,978 & 74,437 & 67 & 789 & 1,405 & 99 \\
\hline
\end{tabular}

* Computed by dividing $\mathrm{CO}_{2}$ emissions (from the Quarterly Fuels Inquiry) by revenue (from the Business Structure Database), where both are observed.

** Computed by taking the UKIS estimate whenever available and imputing the BERD estimate when only it is available. Alternative procedures for combining the UKIS and BERD estimates do not yield substantially different results.

Sources:

${ }^{a}$ Business Structure Database (Office for National Statistics 2012)

${ }^{\mathrm{b}}$ Quarterly Fuels Inquiry (Department of Energy and Climate Change 2011)

${ }^{c}$ EPO Worldwide Patent Statistical Database

d DECC Low Emissions R\&D Survey (Department of Energy and Climate Change and Office for National Statistics 2012)

${ }^{\mathrm{e}}$ UKIS (Department for Business, Innovation and Skills, Office for National Statistics, and Northern Ireland Department of Enterprise, Trade and Investment 2012)

${ }^{\mathrm{f}}$ BERD survey (Office for National Statistics 2011)

\section{Matching Design}

Because EU ETS firms were so different from typical non-ETS firms going in, any number of factors could explain differences in their outcomes. But buried among these millions of firms is something closely resembling a policy experiment.

Two features of the EU ETS's design tell us that the treatment received by suitably matched firms is plausibly uncorrelated with their potential adoption and innovation outcomes. First, the regulatory thresholds of the EU ETS apply at the plant level, and to control administrative costs, only "large" plants are covered. For instance, only ceramics factories with a daily production capacity in excess of 75 tonnes are covered and only paper mills with a production capacity exceeding 20 tonnes per day. ${ }^{16}$ Smaller plants are not regulated under the EU ETS, although the firms that operate them may be just as large in total, as polluting, and as innovative.

\footnotetext{
${ }^{16}$ There is no evidence that British firms successfully manipulated these thresholds or manipulated their plant capacities around the thresholds. It also seems unlikely that they would have much incentive to change plant capacities, given the high cost of doing so and the relatively low cost of EU ETS compliance.
} 
Because regulatory status is determined at the plant level but efficiency and innovation are firm-level characteristics, I can, in principle, find firms that have recently fallen under different regulatory regimes but are of similar size and have historically similar input intensities. The plant-level thresholds, hence, give rise to within-pair variation in firm-level treatment that looks as if it were generated by flipping a coin. ${ }^{17}$ My identifying assumption is that conditional on firm-level characteristics, variation in plant capacity does not drive future adoption and innovation outcomes except through its effect on EU ETS status. ${ }^{18}$

A second important feature of the EU ETS is that it used different eligibility criteria from previous carbon pricing policies. This makes it possible to condition on past regulations at the firm level without removing all variation in EU ETS status. This is desirable, too, since I do not have detailed data on the nature of production at each plant. The fact that two firms previously were subject to the same carbon regulations suggests similarities in their production activities beyond what other firm-level variables may reveal. Moreover, this unobserved similarity in the nature of their production makes it more likely that the two firms would have been subject to the same carbon regulations in the future, absent the EU ETS. Control firms previously subject to the same carbon regulations therefore provide the best indication of the counterfactual policy to which EU ETS firms would otherwise have been subject. Conditioning on past regulations mitigates these omitted variable concerns. As discussed earlier, this means that the differences in outcomes measure the EU ETS's effect relative to the counterfactual policies experienced by similar firms outside the program.

One might be worried that firms strategically signed up to CCAs or the UK ETS to delay entry into the more stringent EU ETS. Even if I made sure that the control firms signed up as well, they might have done so expecting adoption and innovation would be so easy that they could overcomply and earn rents from their participation. This would bias the matched comparison against EU ETS firms. There are two important problems with this story, though. First, the main draw of CCAs was that signatories earned an 80 percent discount on the Climate Change Levy. This provided a strong incentive to sign up for CCAs whether or not a firm was anticipating future regulations under the EU ETS, and indeed, the main driver of participation was eligibility (Martin, de Preux, and Wagner 2014). If we are concerned that EU ETS firms signed up to avoid stricter climate regulations, it seems non-ETS firms signed up for exactly the same reason. Second, and more importantly, the list of firms that qualified for delayed entry into the EU ETS was not amended after the exemptions were announced in 2003.19 So the firms that received exemptions could not have known this at the time they signed up for CCAs and the UK ETS.

\footnotetext{
${ }^{17}$ Of course, it is possible for a firm with multiple plants to have only some covered by the EU ETS, but without much loss of information, I define an "EU ETS firm" simply as one that operates at least one plant covered by the EU ETS. This binary approximation of the treatment variable can be used without much sacrifice since there appears to be little variation in the actual share of regulated activities. Based on a sample of 205 EU ETS firms whose plant-level emissions are recorded in the UK's Pollution Inventory (UK Environment Agency 2017), I estimate that the average share of regulated emissions exceeds 90 percent, and nearly three-quarters of ETS firms have a regulated emissions share of 100 percent. See the online Appendix for details and further discussion of multiplant firms.

${ }^{18}$ See the online Appendix for a longer discussion of this assumption and its motivation.

${ }^{19}$ Based on personal communications with Environment Agency staff responsible for implementing the EU ETS.
} 
Table 2-Equivalence Tests for Matched EU ETS $(N=403)$ and Non-ETS Firms $(N=446)$

\begin{tabular}{|c|c|c|c|c|c|}
\hline & $\begin{array}{c}\text { EU ETS } \\
\text { mean }\end{array}$ & $\begin{array}{l}\text { Non-ETS } \\
\text { mean }\end{array}$ & $\begin{array}{l}\text { Equivalence } \\
\text { range }\end{array}$ & $\begin{array}{l}\text { Signed-rank } \\
\text { test } p \text {-value }\end{array}$ & $\begin{array}{c}\text { Paired } t \text {-test } \\
p \text {-value }\end{array}$ \\
\hline \multicolumn{6}{|l|}{ Firm basics } \\
\hline Revenues $(£ 1,000 \mathrm{~s})$ & 520,473 & 367,531 & $\pm 461,220$ & $<0.001$ & $<0.001$ \\
\hline Employees & 1,595 & 1,059 & \pm 796 & $<0.001$ & 0.011 \\
\hline Year of birth & 1988 & 1988 & \pm 2 & $<0.001$ & $<0.001$ \\
\hline Economic sector (3-digit) & Exact match & - & - & - & - \\
\hline \multicolumn{6}{|l|}{ Efficiency } \\
\hline $\mathrm{CO}_{2}$ intensity $\left(\mathrm{tCO}_{2} / £ 1,000\right)$ & 0.292 & 0.252 & \pm 0.093 & 0.015 & 0.025 \\
\hline Labor intensity (employees $/ £ 1,000)$ & 0.011 & 0.012 & \pm 0.003 & 0.004 & 0.005 \\
\hline \multicolumn{6}{|l|}{ Patenting } \\
\hline Low-carbon patents & 0.018 & 0.015 & \pm 0.029 & $0.642^{L P}$ & 0.002 \\
\hline All other patents & 0.613 & 0.616 & \pm 0.635 & 0.049 & $<0.001$ \\
\hline \multicolumn{6}{|l|}{ R\&D spending } \\
\hline Low-carbon patent share & 0.004 & 0.002 & \pm 0.007 & $0.783^{L P}$ & 0.028 \\
\hline R\&D spending (£1,000s) & 10,193 & 7,996 & $\pm 8,975$ & $<0.001$ & 0.005 \\
\hline \multicolumn{6}{|l|}{ Regulatory history } \\
\hline CCA participation & 0.479 & 0.367 & \pm 0.049 & - & 0.781 \\
\hline UK ETS participation & Undisclosed & Undisclosed & - & - & - \\
\hline CCL bill $(£ 1,000)$ & 98 & 81 & \pm 35 & 0.044 & 0.024 \\
\hline R\&D support $(£ 1,000)$ & 845 & 888 & $\pm 1,656$ & $<0.001$ & $<0.001$ \\
\hline
\end{tabular}

Notes: The first two columns report the means for matched EU ETS and non-ETS firms, using all pretreatment years in the data. Economic sector is exactly matched at the three-digit level. CCA and UK ETS participation are reported as proportions. The empirical distributions of EU ETS and non-ETS firms are judged to be substantively equivalent if the difference lies within the "equivalence range" reported in the third column, specified as \pm 0.2 standard deviations of the pooled sample (Cochran and Rubin 1973, Ho and Imai 2006). The fourth and fifth columns report the $p$-values for Wilcoxon's signed-rank test and the paired $t$-test of the null hypothesis that the difference between distributions lies outside the equivalence range. $L P$ indicates low statistical power. The signed-rank statistic depends only on discordant pairs, so the effective sample size is small for covariates with a large proportion of zeros, in this case patent filings and R\&D spending. The test can then fail to reject at the 5 percent level both that the difference is inside and outside the equivalence range. The paired $t$-test treats concordant pairs as evidence against the hypothesis of difference and will therefore tend to reject it in favor of equivalence when a covariate has a large proportion of zeros. I report the results from both tests, although favor the signed-rank test for patenting and R\&D spending as concordant zero-pairs do not seem to provide much evidence against the hypothesis of difference. Wilcoxon's signed-rank test cannot be performed for CCA and UK ETS participation since they are binary variables. Figures on UK ETS participation could not be publicly disclosed but are available through the UK Data Service.

The design and implementation of the EU ETS make it clear that variation in treatment within suitably matched pairs is driven by exogenous plant-level capacity thresholds. I match on all variables listed in Table 2 to construct these pairs and impose the further restriction that both members of a pair must be drawn from the same economic sector. ${ }^{20}$ Aside from a few basic firm characteristics (average pretreatment revenues, employees, economic sector, age of the firm) and their regulatory histories, the matching variables are the same as the outcomes I will analyze

\footnotetext{
${ }^{20}$ Economic sectors are defined at the three-digit level for the NACE industry classification. To give a sense of how these sectors are defined, in the power sector, "electric power generation, transmission and distribution" is separate from "manufacture of gas; distribution of gaseous fuels through mains," and "steam and air conditioning supply." Within manufacturing, "manufacture of pulp, paper and paperboard" is separate from "manufacture of articles of paper and paperboard," and "manufacture of motor vehicles" is separate from "manufacture of bodies (coachwork) for motor vehicles; manufacture of trailers and semi-trailers," and "manufacture of parts and accessories for motor vehicles." "Preparation and spinning of textile fibres" is distinct from "weaving of textiles," which is distinct from "finishing of textiles."
} 
later. Finally, firms are matched on the pattern of missing values to account for the possibility that data are not missing at random. ${ }^{21}$

Each EU ETS firm was first matched to its nearest neighbors. ${ }^{22}$ I then excluded iteratively pairs that most undermine covariate balance. This resulted in the removal of 42 EU ETS firms that lacked close matches. The final matched sample includes 403 ETS firms and 446 non-ETS firms. I have taken the average when I find several equally close matches so that I have the weighted equivalent of one non-ETS firm for every ETS firm. This matched sample was locked in before viewing the data on outcomes. Even so, to show that my conclusions are not sensitive to this precise bias-variance trade-off, I reestimate the main results without first omitting the 42 unbalanced pairs.

This procedure achieves a high degree of covariate balance (Table 2). EU ETS firms are somewhat larger than their matches, although the differences are small relative to the standard deviation. The final two columns of Table 2 report the results of tests for the equivalence of ranks and means, and I can confidently reject the hypothesis that the groups are substantively different. "Difference" is the null hypothesis, and I only reject in favor of "equivalence" if I have sufficient evidence that the difference is within the equivalence range (of 0.2 standard deviations). A small $p$-value is therefore evidence of equivalence. This is a more stringent test of balance than merely failing to reject the null of equivalence (Hartman and Hidalgo 2014).

The sectoral distribution is identical. The baseline levels of efficiency, patenting, and R\&D spending also appear similar across the two groups. ${ }^{23}$ EU ETS firms tended to have slightly larger CCL bills and receive marginally more government support for R\&D, but these differences are neither substantively nor statistically significant. While ETS firms were somewhat more likely to have participated in a CCA or the UK ETS, it amounts to no more than a dozen firms. In any case, it will be prudent later to check that whatever outcomes I observe are not strongly correlated with these imbalances.

The quantile-quantile plots in Figure 5 show that not only are the central tendencies similar but so are the whole distributions of efficiency, patenting, and R\&D. Figure 6 reveals that the outcome variables also exhibit similar pretreatment trends, and in later sections we will see that matching appears to have achieved balance even

\footnotetext{
${ }^{21}$ See the online Appendix for a longer discussion of the choice of matching variables.

${ }^{22}$ The matches were found by conducting a genetic search over the space of generalized Mahalanobis distance metrics. The algorithm, developed by Sekhon (2011), starts by calculating hundreds of variations of the Mahalanobis distances between firms, using different covariate weights, and matching each firm to its nearest neighbors as defined under each distance metric. The matched sets created by this procedure are then evaluated by running the Kolmogorov-Smirnov test for equality of distributions for each covariate. The best distance metric is the one that maximizes the minimum $p$-value for any covariate. In the next generation, hundreds of new distance metrics are generated by perturbing randomly the previous generation's winner, and so on. The process is stopped only once covariate balance reaches a plateau. The final matches are therefore chosen after testing systematically thousands of different distance metrics, so we can be confident that no superior set of matches can be found among the six million non-ETS firms. For technical reasons, it was not computationally feasible to execute this genetic search algorithm on the entire population of firms. I therefore used coarsened exact matching as an initial step to discard quickly and efficiently a large number of unregulated firms that were poor candidates for matching (Iacus, King, and Porro 2012). See the online Appendix for additional details on the matching.

${ }^{23}$ I have used the share of low-carbon patents to proxy low-carbon R\&D spending, since the latter is only observed in the treatment period, from DECC's low emissions R\&D survey. This is in line with other studies that have tried to proxy firm-level corporate low-carbon R\&D spending.
} 
Panel A. Efficiency

Tonnes of $\mathrm{CO}_{2}$ and employees

Per $£ 1,000$ of revenue

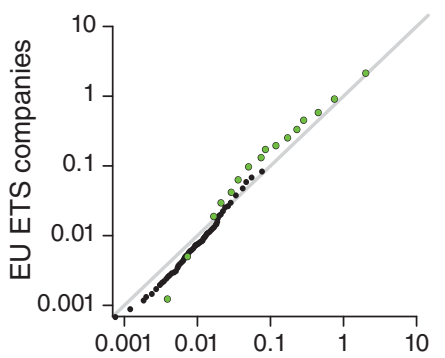

Panel B. Patents

Low-carbon and other Total number

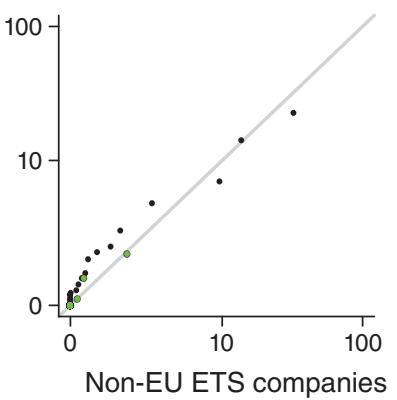

Panel C. R\&D

Total R\&D spending Million $£$

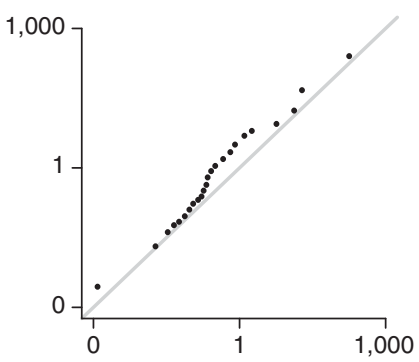

Figure 5. Comparison of Matched EU ETS ANd Non-ETS Firms

Notes: Panel A shows the empirical quantile-quantile (e-QQ) plot for average annual $\mathrm{CO}_{2}$ intensity (in green, which looks like gray circles when printed in black and white) and labor intensity (in black) between 2000 and entry into the EU ETS. The points would all be on the $45^{\circ}$ line if the distributions of the EU ETS and non-ETS firms were exactly the same. Panel B shows the e-QQ plot for the average annual number of low-carbon patents filed (in green, gray when printed in black and white) and all other patents (in black) over the same period. Panel C shows the e-QQ plot for the average annual R\&D spending, which cannot be separated into low-carbon and other. Scales are logarithmic. To comply with UK Data Service disclosure rules, each point represents a percentile pair rather than a firm pair. The firm-pair version of this graph is available to view through the UK Data Service.
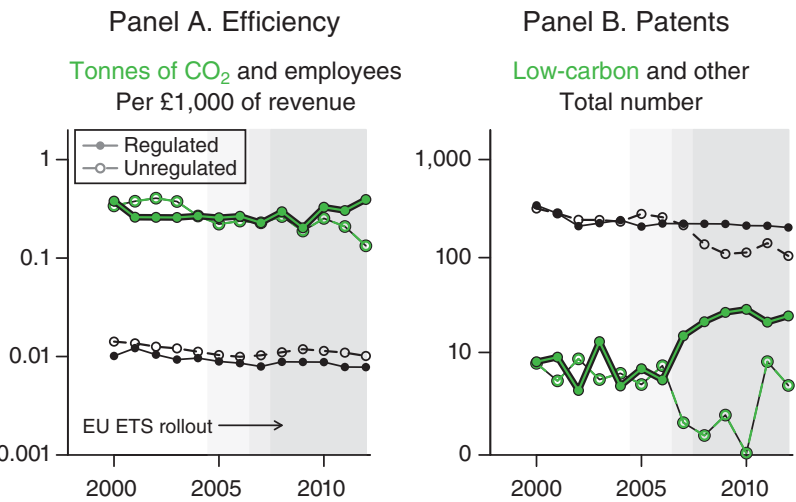

Panel C. R\&D

Low-carbon and total Million £

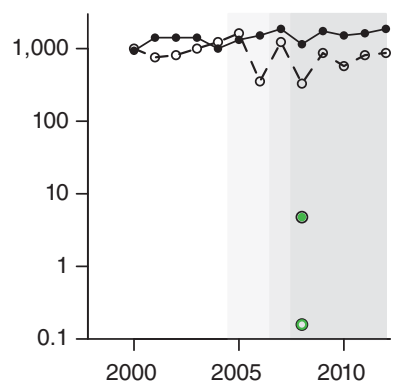

Figure 6. Adoption and InNOVAtion of Matched EU ETS AND Non-ETS Firms

Notes: The gray shading indicates how many of the EU ETS firms were regulated under this program at different points in time. Panel A plots average annual tonnes of $\mathrm{CO}_{2}$ and number of employees that matched firms used per $£ 1,000$ of revenues they generate. Panel B plots the total number of patents filed annually to protect low-carbon and other technologies, respectively. Panel C plots total annual R\&D spending and, for the year 2008, the total R\&D spending directed toward developing low-carbon technologies. The colors in the titles provide an implicit legend: the green lines refer to low-carbon measures, while the black lines refer to their complements. When printed in black and white, the green looks like lines and circles filled in with gray. To deal with the fact that non-ETS firms filed zero low-carbon patents in 2010, the scale of panel B is adjusted to reflect that I have added 1 to all counts before taking the logarithm.

on some variables that were not explicitly matched. All of this provides reason to believe that the matched set approximates the statistical conditions of a true experiment. These EU ETS and non-ETS firms are statistically indistinguishable on the 
eve of regulation, so we have no basis on which to predict that one group will adopt or innovate more than the other, aside from the influence of the EU ETS.

\section{Estimation Method}

The matched dataset looks like any other panel, so it is straightforward to compute standard estimators such as difference-in-means and difference-in-differences. I report both later. But patenting and R\&D spending are both censored at zero, and it is a common feature of these data that most firms do not innovate at all. The traditional Tobit estimator is often used to account for this kind of censoring, but it does not lend itself to my setting. I would have to explicitly model the propensity to innovate. This is by no means straightforward, and the possibility of misspecifying the model carries with it the risk of introducing new unknown biases. The analogous maximum likelihood estimator will also generally be inconsistent (Chay and Powell 2001).

Fortunately, the matched design can be leveraged to obtain a parsimonious and powerful estimator that adjusts for zero-censoring without an explicit first stage and without exclusion restrictions (Rosenbaum 2010, Calel and Dechezleprêtre 2016). It starts from the observation that if the EU ETS had no effect, being labeled an "EU ETS firm" holds no predictive power. In a given treated firm-control firm pair $n$, the outcome of the treated firm, $T_{n}$, would turn out larger than the control firm's, $C_{n}$, just as frequently as it turned out smaller ( $n$ indexes pairs). The observed treated-minus-control differences, $\delta_{n}$, would be positive as often as they were negative.

If the EU ETS caused treated firms to file $\tau$ extra patents, however, one would observe an excess of positive $\delta_{n}$ s compared to what is expected by chance. I can then recover the effect on patenting by subtracting different hypothetical values, $\hat{\tau}$, from the treated outcomes and testing to see which one restores the data to the known null distribution of $\delta_{n}$ s. That is the Hodges-Lehmann point estimate, and its confidence interval is formed by the set of $\hat{\tau} \mathrm{s}$ that cannot be rejected at a given significance level (Rosenbaum 2013).

To calculate $\delta_{n}$ for different values of $\hat{\tau}$, I use the simplest additive treatment effect model that also adjusts for censoring at zero:

$$
\delta_{n}= \begin{cases}\max \left(T_{n}-\hat{\tau}, 0\right)-C_{n} & \text { if } \hat{\tau} \geq 0 \\ T_{n}-\max \left(C_{n}-\hat{\tau}, 0\right) & \text { otherwise. }\end{cases}
$$

I follow standard practice and use Wilcoxon's signed-rank test to determine whether the $\delta_{n}$ s deviate from the null distribution. This test has the advantage that it is built on exactly the same statistical logic as a paired randomized experiment. The only assumption it makes is that matched firms had conditionally equal ex ante chances of achieving superior outcomes, which is precisely what I hope I have accomplished by matching. 24

\footnotetext{
${ }^{24}$ One further advantage of this estimator is that it retains statistical power even with highly nonnormal data, which I have. Statistical power is very valuable since I am working with a relatively small number of matched
} 
Table 3-Matching Estimates of the Effects of the EU ETS

\begin{tabular}{lcr}
\hline \hline & Hodges-Lehmann point estimate & $p$-value \\
\hline Efficiency $\left(\mathrm{tCO}_{2}\right.$ or employees per £1,000) & & \\
$\mathrm{CO}_{2}$ intensity & 0.078 & 0.042 \\
Labor intensity & -0.002 & $<0.001$ \\
Patenting (number of patents) & 0.415 & \\
$\quad$ Low-carbon patents & 0.130 & 0.079 \\
Other patents & & 0.167 \\
R\&D spending (£1,000s) & 200.000 & \\
$\quad$ Low-carbon R\&D & 514.000 & $<0.046$ \\
Total R\&D & & $<0.001$ \\
\hline
\end{tabular}

Notes: The first column reports the location shift parameter that maximizes the $p$-value of Wilcoxon's signed-rank statistic. The accompanying $p$-values are computed under the null hypothesis that the EU ETS has had no effect.

\section{Results}

\section{A. Efficiency}

My estimates suggest that the EU ETS has not encouraged substantial adoption among capped firms. Matched ETS and non-ETS firms followed similar trends in the pretreatment period (see Figure 6). If the EU ETS had spurred widespread adoption of abatement technologies, we would then expect $\mathrm{CO}_{2}$ intensities to decline, but panel A of Figure 6 instead shows an increase for ETS firms. Indeed, the point estimate, reported in Table 3, is that the EU ETS caused a typical regulated firm to increase the $\mathrm{CO}_{2}$ intensity of its output by 0.078 tonnes per $£ 1,000$ of revenue. This translates into an average increase of 20.7 percent. For the median revenue earner, this would imply an additional 4,225 tonnes of $\mathrm{CO}_{2}$ annually, assuming that the EU ETS did not also affect revenues.

This conclusion depends on a few highly leveraged observations, though, and disappears with the removal of only a few pairs. ${ }^{25}$ Together with the late timing of the divergence of $\mathrm{CO}_{2}$ intensities seen in Figure 6, this estimate should not be read as strong evidence that the EU ETS has caused $\mathrm{CO}_{2}$ intensities to increase. Rather, it adds to the number of studies that have looked for reductions in $\mathrm{CO}_{2}$ intensity in the EU ETS and turned up no evidence of it (Löfgren et al. 2013; Widerberg and Wråke 2009; Klemetsen, Rosendahl, and Jakobsen 2016; Jaraitė and Di Maria 2016). The absence of evidence is now starting to show, instead, that the EU ETS has not spurred adoption.

The apparent lack of adoption could, in principle, be explained by some unobserved factor that makes EU ETS firms slower to adopt efficiency-enhancing

pairs, a significant proportion of which have identical zero outcomes.

${ }^{25}$ Removing a single outlying pair raises the $p$-value above 0.05 , and with the removal of five pairs it exceeds 0.25. Meanwhile, the point estimate falls from 0.078 to 0.065 to 0.025 . See the online Appendix for full details, including an examination of outlier sensitivity of all key estimates. 
technologies in general. This alternative explanation seems implausible, however, given that they reduced their labor intensity by 0.002 employees more per $£ 1,000$ of revenue than their unregulated counterparts or 16.7 percent in proportional terms. ${ }^{26}$

\section{B. Patenting}

My estimates suggest that the EU ETS has encouraged substantial low-carbon patenting among capped firms. The most dramatic feature of Figure 6 is the divergence of low-carbon patenting after the introduction of the EU ETS. I estimate that the EU ETS has encouraged regulated firms to file an additional 0.415 low-carbon patents per year (Table 3), which is remarkably close to the two additional patents over a five-year period reported by Calel and Dechezleprêtre (2016). The effective sample size is small since most firms never file low-carbon patents, but the 90 percent confidence interval narrowly excludes $0(0.09,11.89)$. Under the conservative assumption that the matched non-ETS firms are not responding to the EU ETS, these numbers imply that ETS firms collectively would have filed $29(10,138)$ fewer low-carbon patents under the control condition, which translates into the EU ETS having caused low-carbon patenting to increase by 25 percent compared with the counterfactual. Assuming the effect was the same for the 42 omitted ETS firms (to which I return later), the estimate implies a total of 64 additional low-carbon patents in 2005-2012, a 10 percent increase against the counterfactual. ${ }^{27}$

Patenting for all other technologies fell in both groups, albeit slightly faster among unregulated firms. The estimated treatment effect of $0.13(-0.10,0.43)$ implies that EU ETS firms filed $62(-51,157)$ more non-low-carbon patents than they otherwise would have or a 4 percent ( -3 percent, 11 percent) increase. If the effect was the same for the 42 omitted ETS firms, a total of 90 additional non-low-carbon patents were filed in 2005-2012 or a 1.3 percent increase. The confidence interval admits the possibility that the EU ETS increased low-carbon patenting at the expense of patenting for other technologies (Popp and Newell 2012) but assigns much greater probability to the outcome that regulated firms increased their overall patenting while disproportionately favoring low-carbon technologies.

The EU ETS regulates only a small fraction of British firms, and when averaged across the whole country, these effects amount to a $0.10-0.25$ percent increase in total low-carbon patenting and a $0.02-0.04$ percent increase in all other patenting. While such changes may seem small, it is instructive to consider how much it would cost to accomplish the same outcome by other means. I estimate that the EU ETS is responsible for adding 91 patents over the period (29 low-carbon and 62 others) or 154 if I extrapolate the point estimates to the full population of British ETS firms (64 low-carbon and 90 others). Dechezleprêtre et al. (2016) estimate that £1 million spent through the UK's R\&D Tax Relief Scheme yields about 1.12 additional patents. If this is accurate, it would take on average $£ 81-138$ million in targeted tax

\footnotetext{
${ }^{26}$ As a matter of economic theory, there is no difficulty explaining why a regulation that increases the relative price of one factor of production would encourage increased efficiency in another. Efficiency improvements in the latter factor may be technologically complementary.

${ }^{27}$ The denominator increases disproportionately since the omitted firms file more patents than the average. Even though the absolute increase is larger, the proportional increase is smaller.
} 
expenditures to bring about the same increase in patenting as the EU ETS. By contrast, the EU ETS raised $£ 1.3$ billion in this period for the British government from the auctioning of emissions permits (UK Department of Energy and Climate Change and Barker 2012) while creating important benefits beyond innovation, such as emissions reductions.

My estimated effects on patenting are also conservative for several reasons. Although some new energy efficiency patents are included in the Y02 class, they would not be counted as evidence of low-carbon innovation here. Even if the EU ETS led to higher electricity prices and an increase in energy efficiency patents, that would have affected all firms, whether covered by the EU ETS or not. The comparison of the patenting of capped and uncapped firms will then difference out those energy efficiency patents. My estimate therefore refers specifically to technologies aiming to reduce direct emissions, and any effect of the EU ETS on energy efficiency patenting should be added to my estimates to get the EU ETS's total effect. More generally, any patents by unregulated firms will not be counted as an effect of the EU ETS, even if those innovations were designed to be sold to regulated firms. If the effects on these other firms and technologies are significant, my estimates provide a lower bound on the EU ETS's effect on directed technological change. ${ }^{28}$

\section{C. $R \& D$ Spending}

My estimates suggest that the EU ETS has encouraged substantial low-carbon R\&D spending among capped firms. Low-carbon R\&D spending can tell us whether firms are merely rushing to patent what is already in their pipelines or making new investments in innovation. These expenditures are almost never observable, but a unique survey was conducted in the United Kingdom. Data were collected for 2008, recording low-carbon R\&D spending for 27 of the ETS and 21 of the non-ETS firms in my matched sample. ${ }^{29}$ Based on this sample, EU ETS firms were substantially more likely to undertake low-carbon $\mathrm{R} \& \mathrm{D}$ (odds ratio $=6.76, p=0.064$ ). I estimate that the EU ETS increased low-carbon R\&D spending by $£ 200,000$ (with a 90 percent confidence interval of $£ 65,000$ to $£ 656,000$ ), which translates into a 32 percent (11 percent, 126 percent) increase. ${ }^{30}$ If 2008 was a representative posttreatment year, it would mean that the EU ETS induced regulated firms to spend an additional $£ 5.8$ million on low-carbon R\&D in 2005-2012 (£2.4 million, £14.0 million). If the omitted EU ETS firms responded the same way, the total increase would have been $£ 11.6$ million ( $£ 4.3$ million, $£ 29.6$ million) or a 7 percent increase ( 2 percent, 19 percent).

\footnotetext{
${ }^{28}$ See the online Appendix for a lengthier discussion of how the measurement and mismeasurement of low-carbon patents would bias my analysis against finding an effect.

${ }^{29}$ The DECC low-carbon R\&D survey was sent to a sample of roughly 4,500 of the largest innovators in the United Kingdom and had a response rate of just over 50 percent. The sampling frame does not overlap well with the set of matched ETS and non-ETS firms. Only 83 ETS firms and 42 non-ETS firms in my matched sample were surveyed, and only 27 of the ETS and 21 of the non-ETS firms responded. The difference in response rates is just about significant at conventional levels; odds ratio $=0.485, p=0.079$.

${ }^{30}$ Because low-carbon R\&D spending is observed for relatively few firms, the magnitude of the point estimate does respond to the removal of the most outlying pairs. Leaving out the five farthest outliers reduces the point estimate to $£ 65,000$, though it remains just about significantly positive, with $p=0.084$. The online Appendix provides full details, including an examination of outlier sensitivity of all key estimates.
} 
Additional evidence comes from total R\&D spending, which I observe over the whole study period and also for more firms. Absent low-carbon R\&D crowding out other R\&D activities, I would expect the effect on total R\&D to be at least as large as on low-carbon $R \& D$. On the other hand, an estimated increase on total R\&D spending that is much larger would be implausible. I estimate that the EU ETS was responsible for an additional $£ 514,000$ ( $£ 251,000, £ 1,002,000$ ) per firm and year, which translates into a proportional increase of 3 percent ( 2 percent, 5 percent) of total R\&D spending. Cumulatively, this implies an additional expenditure of $£ 346.7$ million (£192.5 million, £579.9 million) from 2005 to 2012. Extrapolation to include the omitted EU ETS firms gives a total increase of $£ 443.3$ million (£242.9 million, £754.4 million). These estimates suggest that the EU ETS has had a disproportionate positive impact on low-carbon R\&D without cannibalizing resources intended for other $\mathrm{R} \& \mathrm{D}$ activities. If anything, they suggest a mild crowding-in, consistent with my estimates of increased patenting. The signs and magnitudes of these estimates are comparable to the effects on patenting, suggesting that my estimates of innovation are picking up a genuine signal.

My estimates imply the EU ETS was responsible for roughly a 1-2 percent increase in overall corporate low-carbon R\&D spending (using the DECC survey's estimated total of $£ 66$ million in 2008) and a $0.4-0.5$ percent increase in total corporate $R \& D$ spending. I can also recast my estimates in equivalent spending on tax credits. Dechezleprêtre et al. (2016) estimate that $£ 1$ million spent on the UK's R\&D Tax Relief Scheme yields $£ 1.7$ million of corporate R\&D spending. It would then take on average $£ 200-260$ million in additional tax spending to bring about something like the $£ 350-450$ million increase in private sector spending that I attribute to the EU ETS. ${ }^{31}$

\section{Robustness}

This section will investigate the robustness of my interpretations to a number of challenges. Unfortunately, available data are sometimes inadequate to obtain small $p$-values for my estimates. Nevertheless, consistency across outcomes, and across studies, provides other reasons for confidence in the general pattern of effects I have estimated.

\section{A. Alternative Specifications}

Since my matching and estimation involved several judgment calls, it behooves me to examine the sensitivity of my conclusions to some of these choices. One key choice was to match exactly within economic sectors defined at the three-digit level. This would ensure, for example, that I match one firm involved in the "manufacture of articles of paper and paperboard" to another, but I can distinguish only at the four-digit level between firms manufacturing different articles of paper-_corrugated paper," "paper stationery," "wallpaper," and so on. Matching

\footnotetext{
${ }^{31}$ The figure would likely be even larger if we could account for the incentive to overstate R\&D spending created by the tax credit but not by the EU ETS.
} 
TABle 4-Alternative Estimates of EU ETS's EFFEcts

\begin{tabular}{lccc}
\hline \hline & $\begin{array}{c}\text { Hodges-Lehmann } \\
\text { (4-digit) }\end{array}$ & $\begin{array}{c}\text { Difference-in- } \\
\text { means }\end{array}$ & $\begin{array}{c}\text { Difference-in- } \\
\text { differences }\end{array}$ \\
\hline Efficiency & 0.029 & 0.111 & 0.076 \\
$\mathrm{CO}_{2}$ intensity $\left(\mathrm{tCO}_{2} / £ 1,000\right)$ & $(0.191)$ & $(0.031)$ & $(0.150)$ \\
& -0.002 & -0.002 & 0.000 \\
Labor intensity (employees/£1,000) & $(<0.001)$ & $(0.009)$ & $(0.994)$ \\
& & & \\
Patenting & 0.155 & 0.038 & 0.035 \\
$\quad$ Low-carbon patents & $(0.198)$ & $(0.251)$ & $(0.246)$ \\
& 0.630 & 0.135 & 0.138 \\
All other patents & $(<0.001)$ & $(0.429)$ & $(0.392)$ \\
& & & - \\
R\&D spending $(£ 1,000 s)$ & 334.500 & 58.000 & - \\
Low-carbon R\&D & $(0.158)$ & $(0.183)$ & $4,791.000$ \\
Total R\&D & $2,144.000$ & $3,269.000$ & $(0.303)$ \\
& $(<0.001)$ & $(0.229)$ & \\
\hline
\end{tabular}

Notes: The parenthetical number below each estimate is the $p$-value associated with a test of the null hypothesis of zero effect. It has not been possible to estimate the difference-in-differences for low-carbon R\&D since this variable is only observed during the posttreatment period.

within four-digit sectors results in weakly greater imbalances on other covariates, but it might still be worth it if the imbalances are not too large. The estimates are reported in Table 4 . Table 4 also reports the conventional difference-in-means and difference-in-differences for the original sample of firms matched at the three-digit level. ${ }^{32}$

When firms are matched at the four-digit level, the estimate on $\mathrm{CO}_{2}$ intensity shrinks toward zero and becomes statistically insignificant. It so happens that $\mathrm{CO}_{2}$ intensity is more balanced in the pretreatment period for this matched sample, so this estimate might further justify a cautious reading of the sign of the main estimate. It is more challenging to interpret the innovation estimates since patenting and $R \& D$ are substantially less balanced in this sample. The estimate on low-carbon patents is much smaller than before, and the estimate on other patents is much larger. Both estimates on $\mathrm{R} \& \mathrm{D}$ are higher than before, but the increase is greatest for non-low-carbon R\&D. Given the much higher baseline levels of patenting and spending on non-low-carbon technologies, though, the proportional increases in patenting and $\mathrm{R} \& \mathrm{D}$ are still largest for low-carbon technologies.

The magnitudes of the difference-in-means and difference-in-differences estimates are not strictly comparable since they do not adjust for censoring. For $\mathrm{CO}_{2}$ intensity and labor intensity, where censoring is not a concern, the estimates are similar to before. For the innovation outcomes, the estimates are generally smaller and less precise, as expected. The estimate on total R\&D spending is surprisingly much larger than before as a result of a few outliers. Means are

\footnotetext{
${ }^{32}$ All of these alternative specifications are reported in full in the online Appendix.
} 
more sensitive to outliers than rank-based estimators, which the larger $p$-values testify to. Since these estimates need to be extrapolated to all treated firms, not just the innovators, they imply somewhat larger aggregate effects on innovation. The emphasis on low-carbon technologies remains but is less pronounced than before.

To summarize, these specifications all produce the same general pattern of estimates: no evident decrease in $\mathrm{CO}_{2}$ intensity, an increase in low-carbon patenting and $R \& D$, along with a proportionately smaller increase in other patenting and R\&D spending. We should clearly acknowledge that quite a bit of uncertainty remains about the precise economic magnitude of the EU ETS's effects, but the general pattern of those effects replicates across specifications.

\section{B. Selection}

Another concern is that my conclusions might be driven by some form of selection. The most obvious source is the omission of 42 EU ETS firms. These firms were set aside precisely because of being exceptional-larger, more polluting, and more innovative. Mindful of using a less credible counterfactual, then, I reestimate my main results with the inclusion of these 42 firms and their closest controls. The substance of the findings is unchanged. If anything, the estimates are slightly larger with greater statistical significance (see the online Appendix for full results).

Another potential source of bias comes from selective exit. If the EU ETS selectively drove out less innovative ETS firms, average patenting and R\&D spending would be inflated without any change in behavior. This is unlikely for at least three reasons. First, because the least innovative firms were also less efficient than the average, one would expect their exit to give rise to lower $\mathrm{CO}_{2}$ intensities. I find the opposite. Second, the differences in patenting and R\&D are partly due to declining investments among control firms. The most innovative control firms would have had to exit to explain this pattern. Finally, EU ETS firms were less likely to exit than non-ETS firms (odds ratio $=0.43 ; p<0.001$ ), nor were there obvious pretreatment differences between the exiting firms and their matched controls.

\section{Leakage}

Strategic shifts of emissions away from firms' EU ETS plants could confound the link between adoption and $\mathrm{CO}_{2}$ intensity. A firm is required to surrender emissions allowances from a coal-burning generator (direct emissions), for instance, but not for electricity purchases (indirect emissions). Since only about one-third of the carbon price was passed on in the form of higher electricity prices in Britain (Fezzi and Bunn 2010), it would have been relatively cheap to comply with the EU ETS by outsourcing energy production (except for electric utilities, of course, which are a small minority of regulated firms). If outsourcing of energy production is considered leakage rather than a legitimate form of adoption, then the link between adoption and $\mathrm{CO}_{2}$ intensity breaks down. As it happens, though, the proportion of total emissions from electricity consumption did not change markedly (Figure 7, panel A). Treated 
Panel A. Outsourcing emissions

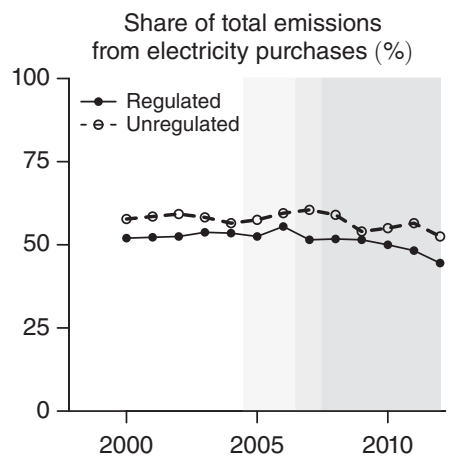

Panel B. Shifting emissions

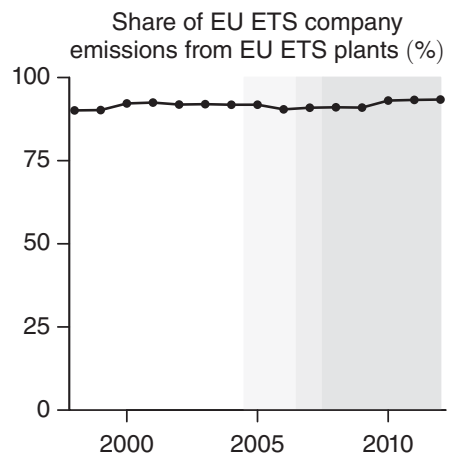

Figure 7. EMISSIONS LEAKAGE

Notes: Panel A plots the average share of total emissions (direct plus indirect) that are from electricity consumption. Indirect emissions are calculated by scaling electricity purchases by the average carbon intensity of grid-delivered electricity. Panel B plots the share of $\mathrm{CO}_{2}$ emissions from EU ETS plants, calculated for a sample of 205 EU ETS firms in the UK's Pollution Inventory (UK Environment Agency 2017). See the online Appendix for details on this dataset.

and control firms track each other closely both before and after the EU ETS came into effect. ${ }^{33}$

Another possibility is a shift in production within multiplant firms toward unregulated plants. If the large ETS plants are more efficient to start, this kind of response could account for the observed increase in $\mathrm{CO}_{2}$ intensity. ${ }^{34} \mathrm{I}$ cannot totally rule out this possibility since $\mathrm{I}$ do not observe the $\mathrm{CO}_{2}$ intensity of every plant. There is no sign that emissions shifted in this way, however, for the sample of 205 EU ETS firms where I observe historical plant-level emissions (Figure 7, panel B). ${ }^{35}$

\section{Other Policies}

Changes in other policies affecting ETS and non-ETS firms differently at the time of introduction of the EU ETS could lead me to misattribute differences in outcomes to the EU ETS. The first place to look is Britain's other carbon pricing policies, which, as we know, were superseded with the rollout of the EU ETS for some firms. Although the matched sample was not perfectly balanced with respect to all these preexisting policies, regression adjustment of the outcomes does not alter the substance of my findings (see the online Appendix).

\footnotetext{
${ }^{33}$ Indirect emissions from electricity purchases or their share of total emissions were not part of the original plan of analysis since they are not covered by the EU ETS. An anonymous referee suggested that this kind of switching to electricity might explain my results and that I could investigate it by multiplying electricity purchases by grid-averaged emissions factors. I report this as a separate robustness test here, and given that ETS and non-ETS firms turn out to have been balanced on this variable all along, there is no reason to re-match with this late-addition covariate. Rather, balancing on covariates not included in the matching provides circumstantial evidence that the match succeeded in creating a sample with the statistical properties needed for identification.

${ }^{34} \mathrm{I}$ am grateful to an anonymous referee for this suggestion.

${ }^{35}$ See the online Appendix for a full discussion of the data on multiplant firms.
} 
Another suspect is government R\&D support. There was an increase in public R\&D spending during this period (Figure 4), and although the matching made sure that firms received similar pretreatment levels of support, the later change might have favored ETS firms. As it happens, though, ETS firms received less government R\&D support. Both groups received roughly $£ 850,000$ per firm per year in R\&D support prior to the EU ETS. After the program started, support for non-ETS firms fell slightly to $£ 753,000$, while support for ETS firms fell dramatically to $£ 102,000$. The UK's R\&D support was targeted more heavily at small and medium-sized businesses. The distribution of government support in my matched sample is highly skewed, so both the magnitude and significance of this change are sensitive to outliers. The sign of the change is robust, however. ${ }^{36}$ Moreover, there is no significant difference in the odds that ETS and non-ETS firms received R\&D support specifically for low-carbon R\&D projects.

\section{E. Spillovers}

The possibility that the EU ETS also encouraged innovation by non-ETS firms makes my results more difficult to interpret. My identification uses the difference between regulated and unregulated firms, but that means that I cannot see any effect the program might have had on the matched unregulated firms. I do not observe much increase in innovation among the matched non-ETS firms, though, so it is unlikely that this effect is large. The bigger question, economically speaking, is how the rest of British innovators responded to the EU ETS.

Two studies of the EU ETS have attempted to estimate this spillover effect using patent data. Calel and Dechezleprêtre (2016) compare unregulated firms that had filed past patent applications jointly with the newly regulated EU ETS firms with otherwise similar unregulated firms, but their estimated spillover is small and insignificant. Miller (2014) makes stronger identifying assumptions and finds a small per-firm spillover that aggregated over all non-ETS firms would be as big as the direct effect itself. This would suggest a doubling of my estimated totals.

To get a sense of the appropriate multiplier in my setting, I look at "top innovators." They are often not regulated polluters themselves nor matched to them, yet they could respond to policy changes that create demand for new technologies. Figure 8 plots the total low-carbon patenting for EU ETS firms along with the 100 most prolific non-ETS patent filers. Low-carbon patenting increases for both groups after 2005, with slight differences in timing. The increase of low-carbon patenting by non-ETS "top innovators" is approximately as large as my estimate of the increase for ETS firms. My estimates then provide a lower bound on the EU ETS's effects on innovation, with an upper bound that could be as much as double that amount.

\footnotetext{
${ }^{36}$ The difference-in-differences is $-£ 655,706$ and varies from $-£ 619,900$ to $-£ 274,700$ in a simple leave-one-out exercise. The $p$-value from a paired $t$-test ranges from 0.04 to 0.36 .
} 


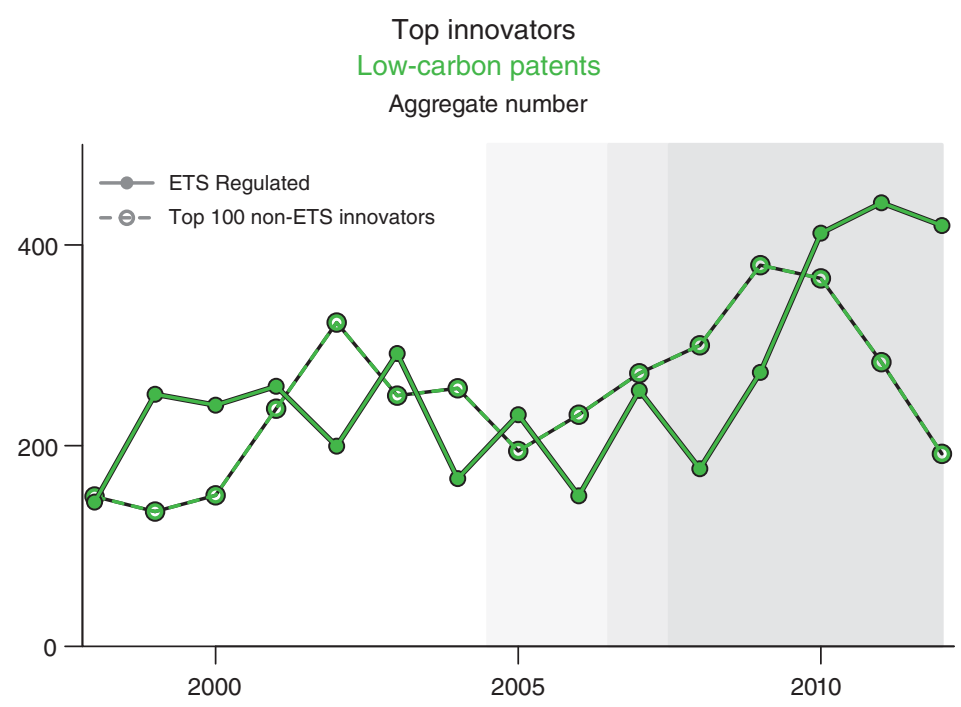

Figure 8. TOP INNOVATORS

Note: Total granted low-carbon patents, by filing year, for EU ETS-regulated firms as well as the 100 non-ETS firms that filed the most patents in the years 2000 through 2004.

\section{Discussion}

One important objective of carbon markets is to achieve abatement by encouraging firms to innovate and become more efficient (Stavins 2007, European Commission 2005, 2012). Historically, emissions reductions under cap-and-trade programs have been achieved primarily through adoption of existing abatement technologies rather than through technological innovation. I find evidence that the EU ETS may have reversed this pattern. Regulated firms have not widely adopted technologies that reduce their $\mathrm{CO}_{2}$ intensity, yet they have increased their patenting and R\&D spending. In particular, low-carbon patenting and low-carbon R\&D spending have increased faster than for other technologies (roughly 20-30 percent versus $3-5$ percent).

New findings that contradict historical patterns should always be viewed with skepticism, and the present study is no exception. Nevertheless, this finding perhaps should not come as a great surprise. Previous cap-and-trade programs have targeted pollutants and polluters that had technologies available to achieve the regulator's long-term abatement targets at reasonable cost. The US phaseout of leaded petroleum, for instance, was specifically aimed at encouraging adoption of existing refining technologies (Kerr and Newell 2003). By the time tradable quotas for CFCs were set up, an economically competitive replacement already existed (Gorman and Solomon 2002, Falkner 2008). At the time when the Acid Rain Program was launched, the technology to scrub sulfur from exhaust was already widely available. On its own, it could have achieved greater emissions cuts than required by the Acid Rain Program (Schmalensee et al. 1998). When relatively mature abatement technologies exist, new technologies are less likely to create major savings in 
compliance costs. It is therefore not surprising that one observes adoption, but not innovation, in these circumstances.

The same preconditions did not exist for the EU ETS, nor do they in carbon markets more generally. The abatement potential of low-cost strategies, such as fuel switching, is limited (Delarue, Voorspools, and D'haeseleer 2008). Achieving longer-term decarbonization goals requires new abatement technologies (Rockström et al. 2017). This leads emitters to ask: Why adopt current abatement technologies that may soon become obsolete anyway, especially as the emissions caps are not binding in the short term? Why not instead develop new low-carbon technologies that will reduce abatement costs more dramatically by the time emissions caps become more stringent? These dynamic considerations shift resources from adoption to innovation (Aghion and Howitt 1992, Mauritzen 2014). They also square well with survey evidence. According to Martin, Wagner, and de Preux (2009), EU ETS firms that expect higher future carbon prices are also more likely to innovate.

If this explanation is correct, it should change how we read evidence from carbon markets. Increased patenting and R\&D signal that new low-carbon technologies are being developed. These technologies should cause abatement costs to decline. We may therefore see greater cost-savings from carbon markets than we have seen from previous cap-and-trade programs, making it feasible to set more ambitious emissions caps and giving us a better chance of ameliorating the worst outcomes of climate change.

Finally, it is worth commenting on the constraints that this and other studies face when trying to answer questions about the effects of carbon markets. I have argued that the estimates presented here and elsewhere show a consistent pattern, but the evidence is ultimately weak by conventional statistical measures. This reflects the unfortunate reality that even after a decade of the world's largest cap-and-trade experiment, the data needed to learn about the effects of the program are still not available. Despite painstaking efforts to obtain the best and most comprehensive data, the effective sample sizes are often small, several of my estimates hover around conventional thresholds of statistical significance, and the economic magnitudes are sensitive to specification. This is an important finding in its own right. Imprecise estimates too often end up in the file drawer even when they reflect our best understanding, but these findings provide critical evidence of the need for improved data collection (DeLong and Lang 1992, Ioannidis and Doucouliagos 2013). Although one may be limited in what can be inferred from imprecise estimates for now, it reminds us-just as China readies itself to launch an even larger carbon market - that the first step in improving regulatory design is to improve data collection practices. More deliberate collection of data on key outcomes at the start of new programs provides a low-cost opportunity to improve our understanding of the effects of future carbon markets.

\section{REFERENCES}

Acemoglu, Daron, Philippe Aghion, Leonardo Bursztyn, and David Hemous. 2012. “The Environment and Directed Technical Change." American Economic Review 102 (1): 131-66.

Aghion, Philippe, Antoine Dechezleprêtre, David Hémous, Ralf Martin, and John Van Reenen. 2016. "Carbon Taxes, Path Dependency, and Directed Technical Change: Evidence from the Auto Industry." Journal of Political Economy 124 (1): 1-51. 
Aghion, Philippe, and Peter Howitt. 1992. "A Model of Growth through Creative Destruction." Econometrica 60 (2): 323-51.

Aghion, Philippe, Reinhilde Veugelers, and Clément Serre. 2009. "Cold Start for the Green Innovation Machine.” Bruegel Policy Contribution (12): 1-12.

Ambec, Stefan, Mark A. Cohen, Stewart Elgie, and Paul Lanoie. 2013. "The Porter Hypothesis at 20: Can Environmental Regulation Enhance Innovation and Competitiveness?" Review of Environmental Economics and Policy 7 (1): 2-22.

Anderson, Barry, Frank Convery, and Corrado Di Maria. 2011. "Technological Change and the EU ETS: The Case of Ireland." Centre for Research on Energy and Environmental Economics and Policy (IEFE) Working Paper 43.

Arora, Ashish, Sharon Belenzon, and Lia Sheer. 2017. "Back to Basics: Why Do Firms Invest in Research?" NBER Working Paper 23187.

-Arvanitis, Spyros, Laurent Donzé, and Nora Sydow. 2010. "Impact of Swiss Technology Policy on Firm Innovation Performance: An Evaluation Based on a Matching Approach." Science and Public Policy 37 (1): 63-78.

- Berman, Eli, and Linda T.M. Bui. 2001. "Environmental Regulation and Labor Demand: Evidence from the South Coast Air Basin." Journal of Public Economics 79 (2): 265-95.

Bowen, Alex, and James Rydge. 2011. "Climate-Change Policy in the United Kingdom." OECD Economic Survey of the United Kingdom 886.

Brunnermeier, Smita B., and Mark A. Cohen. 2003. "Determinants of Environmental Innovation in US Manufacturing Industries." Journal of Environmental Economics and Management 45 (2): 278-93.

Burtraw, Dallas. 2000. "Chapter 4-Innovation under the Tradeable Sulphur Dioxide Emission Permits Programme in the US Electricity Sector." In Innovation and the Environment-Sustainable Development, edited by OECD, 63-84. Paris: OECD.

- Calel, Raphael, and Antoine Dechezleprêtre. 2016. "Environmental Policy and Directed Technological Change: Evidence from the European Carbon Market." Review of Economics and Statistics 98 (1): 173-91.

- Chavas, Jean-Paul, Michael Aliber, and Thomas L. Cox. 1997. "An Analysis of the Source and Nature of Technical Change: The Case of U.S. Agriculture." Review of Economics and Statistics 79 (3): 482-92.

-Chay, Kenneth Y., and James L. Powell. 2001. "Semiparametric Censored Regression Models." Journal of Economic Perspectives 15 (4): 29-42.

Cochran, William G., and Donald B. Rubin. 1973. "Controlling Bias in Observational Studies: A Review." Sankhyā: The Indian Journal of Statistics, Series A 35 (4): 417-46.

Comptroller and Auditor General of the National Audit Office (NAO). 2004. The UK Emissions Trading Scheme-A New Way to Combat Climate Change. London: Stationery Office.

Corsatea, Teodora D., Alessandro Fiorini, Aliki Georgakaki, and Bianca-Nicole Lepsa. 2015. Capacity Mapping: R\&D Investment in SET-Plan Technologies. Brussels: Publications Office of the European Union.

Dechezleprêtre, Antoine, Elias Einiö, Ralf Martin, Kieu-Trang Nguyen, and John Van Reenen. 2016. "Do Tax Incentives for Research Increase Firm Innovation? An RD Design for R\&D." NBER Working Paper 22405.

Dechezleprêtre, Antoine, and Matthieu Glachant. 2014. "Does Foreign Environmental Policy Influence Domestic Innovation? Evidence from the Wind Industry." Environmental and Resource Economics 58: 391-413.

Dechezleprêtre, Antoine, Ralf Martin, and Myra Mohnen. 2014. "Knowledge Spillovers from Clean and Dirty Technologies." Centre for Economic Performance (CEP) Discussion Paper DP1300.

DDekker, Thijs, Herman R.J. Vollebergh, Frans P. de Vries, and Cees A. Withagen. 2012. "Inciting Protocols." Journal of Environmental Economics and Management 64 (1): 45-67.

Delarue, Erik D., A. Denny Ellerman, and William D. D'haeseleer. 2010. "Short-Term CO2 Abatement in the European Power Sector: 2005-2006." Climate Change Economics 1 (2): 113-33.

-Delarue, Erik, Kris Voorspools, and William D'haeseleer. 2008. "Fuel Switching in the Electricity Sector under the EU ETS: Review and Prospective.” Journal of Energy Engineering 134 (2): 40-46.

-DeLong, J. Bradford, and Kevin Lang. 1992. "Are All Economic Hypotheses False?" Journal of Political Economy 100 (6): 1257-72.

Department for Business, Innovation and Skills, Office for National Statistics, and Northern Ireland Department of Enterprise, Trade and Investment. 2012. "UK Innovation Survey, 1994-2010: Secure Data Service Access [computer file]." UK Data Archive [distributor], Colchester, Essex, UK. SN: 6699. 
Department of Energy and Climate Change. 2011. "Quarterly Fuels Inquiry, 1993-2015: Secure Access [computer file]." UK Data Archive [distributor], Colchester, Essex, UK. SN: 6898.

Department of Energy and Climate Change, and Office for National Statistics. 2012. "DECC Low Emissions R\&D Survey, 2008: Secure Data Service Access [computer file]." UK Data Archive [distributor], Colchester, Essex, UK. SN: 6894. http://dx.doi.org/10.5255/UKDA-SN-6894-1.

Dudley, Bob. 2015. BP Statistical Review of World Energy. London: BP p.l.c. https://www.bp.com/en/ global/corporate/energy-economics/statistical-review-of-world-energy.html.

Energy Information Administration (EIA). 2009. Coal Market Module Data Tables: US Coal Production by Coal Market Module Supply Region and Mine Type, 1978-2007. Supplemental Tables to the Annual Energy Outlook 2010. Technical report, EIA. https://www.eia.gov/outlooks/ archive/aeo10/supplement/supref.html.

European Commission. 2005. "EU Action against Climate Change: EU Emissions Trading-An Open Scheme Promoting Global Innovation." Luxembourg: Office for Official Publications of the European Communities.

European Commission. 2012. "Emissions Trading: Annual Compliance Round-up Shows Declining Emissions in 2011." Press Release IP/12/477. https://ec.europa.eu/commission/presscorner/detail/ en/IP_12_477.

European Patent Office (EPO). 2019. "Worldwide Patent Statistical Database (PATSTAT)." European Patent Office, Munich, Germany.

European Union (EU). 2019. "Community Independent Transactions Log (CITL)."

Falkner, Robert. 2008. Business Power and Conflict in International Environmental Politics. New York: Palgrave Macmillan.

- Fezzi, Carlo, and Derek Bunn. 2010. "Structural Analysis of Electricity Demand and Supply Interactions." Oxford Bulletin of Economics and Statistics 72 (6): 827-56.

Fiorini, Alessandro, Aliki Georgakaki, Bianca-Nicole Lepsa, Francesco Pasimeni, and Lourdes Salto Saura Maria. 2016. Estimation of Corporate R\&D Investment in Low-Carbon Energy Technologies: A Methodological Approach. Technical Report JRC101552. Cambridge, UK: University of Cambridge.

-Fischer, Carolyn, Ian W.H. Parry, and William A. Pizer. 2003. "Instrument Choice for Environmental Protection When Technological Innovation Is Endogenous." Journal of Environmental Economics and Management 45 (3): 523-45.

Fowlie, Meredith, Stephen P. Holland, and Erin T. Mansur. 2012. "What Do Emissions Markets Deliver and to Whom? Evidence from Southern California's NOx Trading Program." American Economic Review 102 (2): 965-93.

-Gagelmann, Frank, and Manuel Frondel. 2005. "The Impact of Emission Trading on InnovationScience Fiction or Reality?" European Environment 15 (4): 203-11.

-Gorman, Hugh S., and Barry D. Solomon. 2002. "The Origins and Practice of Emissions Trading." Journal of Policy History 14 (3): 293-320.

- Grubb, Michael, Christian Azar, and U. Martin Persson. 2005. "Allowance Allocation in the European Emissions Trading System: A Commentary." Climate Policy 5 (1): 127-36.

-Hagedoorn, John, and Myriam Cloodt. 2003. "Measuring Innovative Performance: Is There an Advantage in Using Multiple Indicators?" Research Policy 32 (8): 1365-79.

-Hanemann, Michael. 2010. "Cap-and-Trade: A Sufficient or Necessary Condition for Emission Reduction?" Oxford Review of Economic Policy 26 (2): 225-52.

Hartman, Erin E., and F. Daniel Hidalgo. 2014. "What's the Alternative? An Equivalence Approach to Balance and Placebo Tests.” Unpublished.

- Hirshleifer, David, Po-Hsuan Hsu, and Dongmei Li. 2013. "Innovative Efficiency and Stock Returns." Journal of Financial Economics 107 (3): 632-54.

-Ho, Daniel E., and Kosuke Imai. 2006. "Randomization Inference with Natural Experiments." Journal of the American Statistical Association 101 (475): 888-900.

Hoffmann, Volker H. 2007. "EU ETS and Investment Decisions: The Case of the German Electricity Industry." European Management Journal 25 (6): 464-74.

- Iacus, Stefano M., Gary King, and Giuseppe Porro. 2012. "Causal Inference without Balance Checking: Coarsened Exact Matching." Political Analysis 20 (1): 1-24.

Ioannidis, John, and Chris Doucouliagos. 2013. "What's to Know about the Credibility of Empirical Economics?” Journal of Economic Surveys 27 (5): 997-1004.

- Jaffe, Adam B., and Karen Palmer. 1997. "Environmental Regulation and Innovation: A Panel Data Study." Review of Economics and Statistics 79 (4): 610-19. 
Jaraitė, J., and C. Di Maria. 2011. "Did the EU ETS Make a Difference? A Case Study of Ireland and Lithuania." Presented at European Association of Environmental and Resource Economists (EAERE) 18th Annual Conference, Rome, Italy. Cited with author permission.

Jaraitė, Jūratė, and Corrado Di Maria. 2016. "Did the EU ETS Make a Difference? An Empirical Assessment Using Lithuanian Firm-Level Data." Energy Journal 37 (1): 1-23.

- Johnstone, Nick, Ivan Hašččč and David Popp. 2010. "Renewable Energy Policies and Technological Innovation: Evidence Based on Patent Counts." Environmental and Resource Economics 45 (1): 133-55.

Kerr, Suzi, and Richard G. Newell. 2003. "Policy-Induced Technology Adoption: Evidence from the U.S. Lead Phasedown.” Journal of Industrial Economics 51 (3): 317-43.

Klemetsen, Marit E., Knut Einar Rosendahl, and Anja Lund Jakobsen. 2016. "The Impacts of the EU ETS on Norwegian Plants' Environmental and Economic Performance.” Research Department, Statistics Norway Discussion Paper 833.

Lanjouw, Jean O., and Mark Schankerman. 2004. "Patent Quality and Research Productivity: Measuring Innovation with Multiple Indicators." Economic Journal 114 (495): 441-65.

Löfgren, Åsa, Markus Wråke, Tomas Hagberg, and Susanna Roth. 2013. "The Effect of EU-ETS on Swedish Industry's Investment in Carbon Mitigating Technologies." University of Gothenburg Working Paper in Economics 565.

-Martin, B.R. 1996. "The Use of Multiple Indicators in the Assessment of Basic Research." Scientometrics 36: 343-62.

-Martin, Ralf, Laure B. de Preux, and Ulrich J. Wagner. 2014. "The Impact of a Carbon Tax on Manufacturing: Evidence from Microdata." Journal of Public Economics 117: 1-14.

- Martin, Ralf, Mirabelle Muûls, Laure B. de Preux, and Ulrich J. Wagner. 2012. "Anatomy of a Paradox: Management Practices, Organizational Structure and Energy Efficiency." Journal of Environmental Economics and Management 63 (2): 208-23.

Martin, Ralf, Mirabelle Muûls, and Ulrich Wagner. 2011. "Climate Change, Investment and Carbon Markets and Prices-Evidence from Manager Interviews." https://climatepolicyinitiative.org/ wp-content/uploads/2011/12/Climate-Change-Investment-and-Carbon-Markets-and-Prices.pdf.

Martin, Ralf, Ulrich J. Wagner, and Laure B. de Preux. 2009. "The Impacts of the Climate Change Levy on Business: Evidence from Microdata." Centre for Economic Performance (CEP) Discussion Paper DP0917.

-Mauritzen, Johannes. 2014. "Scrapping a Wind Turbine: Policy Changes, Scrapping Incentives and Why Wind Turbines in Good Locations Get Scrapped First." Energy Journal 35 (2): 157-81.

Miller, Steve. 2014. "Indirectly Induced Innovation: Consequences for Environmental Policy Analysis." https://pdfs.semanticscholar.org/8359/8c61d52db7cffd2c191ebeb3c70a95669a6b.pdf.

- Milliman, Scott R., and Raymond Prince. 1989. "Firm Incentives to Promote Technological Change in Pollution Control." Journal of Environmental Economics and Management 17 (3): 247-65.

Newell, Richard G., Adam B. Jaffe, and Robert N. Stavins. 1999. "The Induced Innovation Hypothesis and Energy-Saving Technological Change." Quarterly Journal of Economics 114 (3): 941-75.

OECD. 2009. OECD Patent Statistics Manual. Paris: OECD Publishing.

OECD. 2015. The Measurement of Scientific, Technological and Innovation Activities-Frascati Manual 2015-Guidelines for Collecting and Reporting Data on Research and Experimental Development. Paris: OECD Publishing.

Office for National Statistics. 2011. "Business Expenditure on Research and Development, 1995-2017: Secure Data Service Access [computer file]." UK Data Archive [distributor], Colchester, Essex, UK. SN: 6690. http://dx.doi.org/10.5255/UKDA-SN-6690-1.

Office for National Statistics. 2012. "Business Structure Database, 1997-2018: Secure Data Service Access [computer file]." UK Data Archive [distributor], Colchester, Essex, UK. SN: 6697. http:// dx.doi.org/10.5255/UKDA-SN-6697-10.

-Palmer, Karen, Wallace E. Oates, and Paul R. Portney. 1995. "Tightening Environmental Standards: The Benefit-Cost or the No-Cost Paradigm?” Journal of Economic Perspectives 9 (4): 119-32.

Petrick, Sebastian, and Ulrich Wagner. 2014. "The Impact of Carbon Trading on Industry: Evidence from German Manufacturing Firms.” Kiel Working Paper 1912.

Popp, David. 2002. "Induced Innovation and Energy Prices." American Economic Review 92 (1): 160-80.

Popp, David. 2003. "Pollution Control Innovations and the Clean Air Act of 1990." Journal of Policy Analysis and Management 22 (4): 641-60. 
Popp, David. 2006. "International Innovation and Diffusion of Air Pollution Control Technologies: The Effects of NOX and SO2 Regulation in the US, Japan, and Germany." Journal of Environmental Economics and Management 51 (1): 46-71.

Popp, David, and Richard Newell. 2012. "Where Does Energy R\&D Come from? Examining Crowding out from Energy R\&D." Energy Economics 34 (4): 980-91.

Porter, Michael E. 1991. "Essay: America's Green Strategy." Scientific American 264 (4): 168.

- Requate, Till. 2005. "Dynamic Incentives by Environmental Policy Instruments-A Survey." Ecological Economics 54 (2-3): 175-95.

-Rockström, Johan, Owen Gaffney, Joeri Rogelj, Malte Meinshausen, Nebojsa Nakicenovic, and Hans Joachim Schellnhuber. 2017. “A Roadmap for Rapid Decarbonization.” Science 355 (6331): 1269-71.

Rosenbaum, Paul R. 2010. Design of Observational Studies. Berlin: Springer Science and Business Media.

Rosenbaum, Paul R. 2013. Observational Studies. Berlin: Springer Science and Business Media.

Schleich, Joachim, and Regina Betz. 2005. "Incentives for Energy Efficiency and Innovation in the European Emission Trading System." In Proceedings of the 2005 ECEEE Summer Study-What Works and Who Delivers?, edited by Sophie Attali and Kenya Tillerson, 1495-1506. Stockholm: European Council for an Energy Efficient Economy.

-Schmalensee, Richard, Paul L. Joskow, A. Denny Ellerman, Juan Pablo Montero, and Elizabeth M. Bailey. 1998. "An Interim Evaluation of Sulfur Dioxide Emissions Trading." Journal of Economic Perspectives 12 (3): 53-68.

- Sekhon, Jasjeet S. 2011. "Multivariate and Propensity Score Matching Software with Automated Balance Optimization: The Matching Package for R." Journal of Statistical Software 42 (7): 1-52.

Stavins, Robert N. 2007. "A U.S. Cap-and-Trade System to Address Global Climate Change." John F. Kennedy School for Business and Government, Regulatory Policy Program Working Paper RPP-2007-04.

- Taylor, Margaret R. 2012. "Innovation under Cap-and-Trade Programs." Proceedings of the National Academy of Sciences 109 (13): 4804-09.

- Taylor, Margaret R., Edward S. Rubin, and David A. Hounshell. 2003. "Effect of Government Actions on Technological Innovation for SO2 Control." Environmental Science and Technology 37 (20): 4527-34.

Taylor, Margaret R., Edward S. Rubin, and David A. Hounshell. 2005. "Regulation as the Mother of Innovation: The Case of SO2 Control." Law and Policy 27 (2): 348-78.

- Tomás, R.A.F., F. Ramôa Ribeiro, V.M.S. Santos, J.F.P. Gomes, and J.C.M. Bordado. 2010. "Assessment of the Impact of the European $\mathrm{CO} 2$ Emissions Trading Scheme on the Portuguese Chemical Industry." Energy Policy 38 (1): 626-32.

UK Department of Energy and Climate Change and Gregory Barker. 2012. "UK Confirms Position as Leader in Carbon Markets." https://www.gov.uk/government/news/uk-confirms-position-asleader-in-carbon-markets.

UK Environment Agency. 2017. "Pollution Inventory: 1990-2016." https://data.gov.uk/dataset/ cfd94301-a2f2-48a2-9915-e477ca6d8b7e/pollution-inventory (accessed August 14, 2017).

- Veefkind, V., J. Hurtado-Albir, S. Angelucci, K. Karachalios, and N. Thumm. 2012. "A New EPO Classification Scheme for Climate Change Mitigation Technologies." World Patent Information 34 (2): 106-11.

Wagner, Ulrich, Mirabelle Muûls, Ralf Martin, and Jonathan Colmer. 2014. "The Causal Effects of the European Union Emissions Trading Scheme: Evidence from French Manufacturing Plants." http://conference.iza.org/conference_files/EnvEmpl2014/martin_r7617.pdf.

Widerberg, Anna, and Markus Wråke. 2009. "The Impact of the EU Emissions Trading System on CO2 Intensity in Electricity Generation." University of Gothenburg Working Paper in Economics 361.

-Wiesenthal, Tobias, Guillaume Leduc, Karel Haegeman, and Hans-Günther Schwarz. 2012. "Bottom-up Estimation of Industrial and Public R\&D Investment by Technology in Support of Policy-Making: The Case of Selected Low-Carbon Energy Technologies." Research Policy 41 (1): 116-31.

Wiesenthal, Tobias, Guillaume Leduc, Hans-Günther Schwarz, and Karel Haegeman. 2009. $R \& D$ Investment in the Priority Technologies of the European Strategic Energy Technology Plan. Brussels: Joint Research Centre (JRC), European Commission.

World Bank. 2017. Carbon Pricing Watch 2017. Washington, DC: World Bank. 